\title{
Alúminas porosas: El método de bio-réplica para la síntesis de alúminas estables de alta superficie específica
}

\author{
MÓNICA BENÍTEZ GUERRERO', LUIS PÉREZ MAQUEDA², PILAR PENA CASTRO, JOSÉ PASCUAL COSP¹ \\ 'Unidad Asociada Laboratorio de Materiales y Superficies - Escuela Técnica Superior de Ingenieros Industriales ETSII, Universidad de Málaga, \\ Dr. Ortiz Ramos s/n, 29071 - Málaga, España. \\ ${ }^{2}$ Instituto de Ciencia de Materiales ICMS, Centro Mixto US-CSIC, Américo Vespucio 49, 41092 - Sevilla, España \\ ${ }^{3}$ Instituto de Cerámica y Vidrio ICV-CSIC, Kelsen 5, 28049 - Madrid, España
}

\begin{abstract}
En las últimas décadas el desarrollo de alúminas porosas viene siendo objeto de numerosas investigaciones por las propiedades intrínsecas que tiene el óxido de aluminio, como elevado punto de fusión, baja conductividad térmica, inercia química y resistencia a la corrosión, a las que se unen una elevada superficie específica y permeabilidad, que hacen que encuentren aplicación en multitud de sectores industriales y técnicos.

En aquellos procesos en los que intervengan temperaturas altas, la estabilidad cristalográfica y textural de las alúminas adquiere una importancia significativa; sin embargo, la mayoría de los métodos de preparación conducen hacia la generación de óxidos metaestables, que no encuentran aplicabilidad en procesos de elevada temperatura debido a su transformación hacia la fase alfa, con la consiguiente reducción de superficie.

El presente artículo realiza una revisión de distintas vías de obtención de alúmina porosa de elevada superficie específica, incluyendo los métodos y estrategias que han tenido por objeto la síntesis de alfa-alúmina de alta superficie. Dentro de este marco, el trabajo analiza los resultados obtenidos hasta el momento a través de la bio-réplica de lignocelulósicos, tecnología que permite mimetizar con exactitud la compleja jerarquía estructural de las máscaras hasta diferentes niveles.
\end{abstract}

Palabras clave: óxido de aluminio, $\gamma-\mathrm{Al}_{2} \mathrm{O}_{3}, \alpha-\mathrm{Al}_{2} \mathrm{O}_{3}$, réplica de lignocelulósicos, biomimética.

Porous Aluminas: The biotemplate method for the synthesis of stable high surface area aluminas

Development of porous alumina has been the objective of numerous studies in recent decades, due to the intrinsic properties of aluminium oxide, such as high melting point, low thermal conductivity, chemical inertness and corrosion resistance which, in addition to a high surface area and permeability, make aluminas being used for many different industrial and technical applications.

The crystallographic and textural stability of alumina acquires significant importance in those processes involving high temperatures; however, most of the synthesis methods yield metastable oxides of little interest in high-temperature processes due to the transformation to alpha phase, with the consequent reduction in surface area.

The present article reviews diverse procedures for obtaining porous alumina with high specific surface area, including methods and strategies for preparing high surface alpha-alumina. Within this framework, the paper analyzes the results obtained through bioreplica of lignocellulosic materials. This technology allows preparing aluminas with the complex structural hierarchy of the lignocellulosic templates.

Keywords: Aluminium oxide, $\gamma-\mathrm{Al}_{2} \mathrm{O}_{3^{\prime}} \alpha-\mathrm{Al}_{2} \mathrm{O}_{3^{\prime}}$ lignocellulosic replica, biomimetic.

\section{INTRODUCCIÓN}

En general, la síntesis de estructuras cerámicas porosas con una alta estabilidad térmica y de elevada resistencia, tanto física como química, atraen cada vez una mayor atención en multitud de áreas, especialmente en tecnologías relacionadas con la energía y medioambiente, como separadores gas/líquido, filtros, electrodos porosos para celdas de combustible de óxido sólido (SOFCs), soportes de catalizadores, membranas de micro y ultrafiltración, sensores químicos, así como también en sistemas de aireación de líquidos, sistemas de intercambio iónico, diálisis, separación cromatográfica, sistemas optoelectrónicos, liberación controlada de fármacos y biomateriales para implantes (1-4).
En concreto, las cerámicas porosas de alúmina, por sus excelentes propiedades intrínsecas (bajo peso específico, elevada superficie específica, alta permeabilidad y estabilidad térmica, resistencia a la corrosión) y su bajo coste de producción, presentan un gran interés tecnológico en diversos campos. Destaca su empleo como refractarios, como membranas de separación (5-7) usadas por ejemplo en componentes de filtros de metales fundidos (8) y de gases de alta temperatura (9), y como membranas catalíticas (10) encontrando utilidad tanto en la eliminación de compuestos contaminantes de efluentes gaseosos (11-13) como del agua 
(14-16). Su aplicación en catálisis está ampliamente extendida, debido a la superficie específica y a las propiedades ácidas que presenta (17), usándose como catalizador activo, por ejemplo en las reacciones tipo Claus para transformar el sulfuro de hidrógeno en azufre $(18,19)$, pero especialmente como soporte de catalizadores $(20,21)$, empleado en diferentes procesos industriales, como en la hidrodesulfuración del petróleo (22), en la síntesis de óxido de etileno (23), o en la oxidación de metano (24), entre otros muchos ejemplos recopilados por Fierro (17a). Asimismo, debido a su inercia química y su alta resistencia mecánica (25-27), la alúmina también ha sido utilizada en implantes y prótesis debido a su comprobada biocompatibilidad (28-31), resultando ser su estructura porosa un factor clave en muchas de las investigaciones relacionadas con el aumento de la capacidad de osteointegración de la alúmina (32-36).

Existe una gran variedad de métodos para generar alúminas con porosidades y microestructuras muy diferentes. Entre ellas, la tecnología de bio-réplica o biomáscara posee la capacidad de mimetizar la arquitectura porosa de los materiales naturales, a niveles macro, meso, micro e incluso nanoestructural, posibilitando la síntesis de cerámicas con carácter macro y microcelular, así como la selección y optimización del tipo de porosidad deseada: homogénea, heterogénea, isotrópica o anisotrópica, difíciles de obtener por técnicas convencionales $(37,38)$.

Las propiedades que fundamentalmente determinan la aplicabilidad de las alúminas porosas, como son las características texturales (superficie específica, distribución y volumen de poros) y químicas (proporción y distribución de centros activos), están condicionadas por la transformación de fases que experimenta el óxido de aluminio. La estructura estable de alfa-alúmina, que se obtiene a temperaturas entre 1100 y $1300{ }^{\circ} \mathrm{C}$, presenta baja superficie específica al experimentar la alúmina procesos de sinterización y crecimiento cristalino conforme aumenta la temperatura. Sin embargo, precisamente, son su inercia química y su estabilidad térmica las cualidades que la convierten en una cerámica polivalente de interés generalizado. La búsqueda de soluciones que aumenten los valores de superficie específica de la alúmina a temperaturas elevadas, con objeto de incrementar la duración, eficiencia y calidad de la misma en servicio, y reducir costes de operación y mantenimiento, no ha cesado.

El propósito de este artículo es múltiple. Por un lado, ofrecer una breve revisión de los principales cambios estructurales experimentados durante la transformación de fases del óxido de aluminio. Por otro, recopilar y establecer una clasificación de los principales métodos de síntesis de alúmina porosa y de elevada superficie específica investigados hasta el momento, así como los procedimientos y tácticas conducentes a la generación de alfa-alúmina de alta superficie específica. Por último, exponer los resultados obtenidos relativos a la síntesis de alúmina por bio-réplica de lignocelulósicos.

\section{2. ÓXIDOS DE ALUMINIO}

El óxido de aluminio puede presentar muy diversas estructuras cristalinas, grado de hidratación e impurezas, siendo las de mayor uso cerámico la $\alpha$-alúmina, la $\gamma$-alúmina y el hidróxido de aluminio $\gamma-\mathrm{Al}(\mathrm{OH})_{3}$. La forma natural de alúmina anhidra se denomina corindón, de estructura $\alpha-\mathrm{Al}_{2} \mathrm{O}_{3}$.
Los oxo/hidróxidos naturales, considerados por algunos investigadores como formas hidratadas, tienen tres tipos de estructuras, bohemita (o boehmita) $\mathrm{AlO}(\mathrm{OH})$, diásporo $\mathrm{AlO}(\mathrm{OH})$ y gibbsita (o hidrargilita) $\mathrm{Al}(\mathrm{OH})_{3}$. Además existen otras tres formas importantes de hidróxido de aluminio que son bayerita, nordstrandita y doyleita (39).

La nomenclatura de los oxo/hidróxidos, recogida en la Tabla I, puede llevar a confusión con la de las propias fases cristalográficas de alúmina. La clasificación establecida por Haber (40) está basada en el producto final obtenido por calcinación, alfa y gamma-alúmina. Sin embargo, en la nomenclatura establecida por Frary (41), adoptada por los laboratorios de investigación de Alcoa, las letras griegas $\alpha$ y $\beta$ designan la abundancia relativa natural. El sistema Haber de nomenclatura se ha usado en general en Europa, mientras que el de Alcoa en Estados Unidos (42a).

TABla I NOMENClATURA DE LOS HIDRÓXIDOS DE ALUMINIO

\begin{tabular}{|c|c|c|c|}
\hline \multicolumn{2}{|c|}{ Hidróxidos } & Alcoa & Haber \\
\hline Gibosita & $\mathrm{Al}(\mathrm{OH})_{3}$ & $\alpha-\mathrm{Al}_{2} \mathrm{O}_{3} \cdot 3 \mathrm{H}_{2} \mathrm{O}$ & $\gamma-\mathrm{Al}(\mathrm{OH})_{3}$ \\
\hline Bayerita & $\mathrm{Al}(\mathrm{OH})_{3}$ & $\beta-\mathrm{Al}_{2} \mathrm{O}_{3} \cdot 3 \mathrm{H}_{2} \mathrm{O}$ & $\alpha-\mathrm{Al}(\mathrm{OH})_{3}$ \\
\hline Nordstrandita & $\mathrm{Al}(\mathrm{OH})_{3}$ & & \\
\hline Doyleita & $\mathrm{Al}(\mathrm{OH})_{3}$ & & \\
\hline Bohemita & $\mathrm{AlOOH}$ & $\alpha-\mathrm{Al}_{2} \mathrm{O}_{3} \cdot \mathrm{H}_{2} \mathrm{O}$ & $\gamma-\mathrm{AlOOH}$ \\
\hline Diásporo & $\mathrm{AlOOH}$ & $\beta-\mathrm{Al}_{2} \mathrm{O}_{3} \cdot \mathrm{H}_{2} \mathrm{O}$ & $\alpha-\mathrm{AlOOH}$ \\
\hline
\end{tabular}

\section{Transformación de fases}

Por deshidratación de los oxo/hidróxidos de aluminio se obtienen distintas fases cristalográficas de alúmina dependiendo del material de partida, las condiciones de síntesis y la temperatura de calcinación. Termodinámicamente, la forma cristalina más estable es $\alpha-\mathrm{Al}_{2} \mathrm{O}_{3}$. El resto de fases se denominan en general alúminas de transición (debido a su naturaleza metaestable en comparación con la alfa-alúmina) aunque muchos autores las denominan conjuntamente gammaalúminas. Lippens (43) las clasificó en dos grupos: i) alúminas de transición de baja temperatura, que deshidratan por debajo de $600{ }^{\circ} \mathrm{C}$ y contienen hasta un $0.6 \% \mathrm{H}_{2} \mathrm{O}($ ro $(\rho)$, chi $(\chi)$, eta ( $\eta$ ) y gamma $(\gamma)$-alúmina); ii) alúminas de transición de alta temperatura, prácticamente anhidras, obtenidas entre $900 \mathrm{y}$ $1000{ }^{\circ} \mathrm{C}($ kappa $(\kappa)$, delta $(\delta)$ y tita ( $\theta)$-alúmina).

Las alúminas $\chi, \eta, \gamma, \mathrm{y} \delta$ presentan estructuras cúbicas y tetragonales, que pueden considerarse redes tipo espinela $\left(\mathrm{Mg}^{\mathrm{IV}}\left[\mathrm{Al}^{\mathrm{VI}}{ }_{2} \mathrm{O}_{4}\right)\right.$ distorsionadas, con defectos estructurales. Los átomos de oxígeno ocupan las posiciones de una red cúbica centrada en las caras, y los cationes aluminio ocupan huecos tanto de coordinación octaédrica como tetraédrica, por lo que existen vacantes catiónicas (representadas como $\square$ ) que mantienen la neutralidad eléctrica del conjunto, $\mathrm{Al}_{8 / 3} \square_{1 / 3} \mathrm{O}_{4}$ (44). Numerosas investigaciones indican que la proporción de cationes aluminio en huecos octaédricos es de 2 a 3 veces superior a los que ocupan posiciones tetraédricas (45-47). Aunque diversos autores virtualmente localizan las vacantes catiónicas en sitios preferentemente tetraédricos u octaédricos dependiendo del tipo de alúmina (48-51), una visión más realista consiste en una distribución aleatoria de las mismas $(52,53)$. Si se tiene en cuenta los grupos hidroxilos estructurales que contienen estas alúminas, su descripción queda mejor representada por una fórmula del tipo $\mathrm{Al}_{8 / 3} \square_{\mathrm{X}} \mathrm{O}_{4-\mathrm{Y} / 2}(\mathrm{OH})_{\mathrm{Y}}$ 


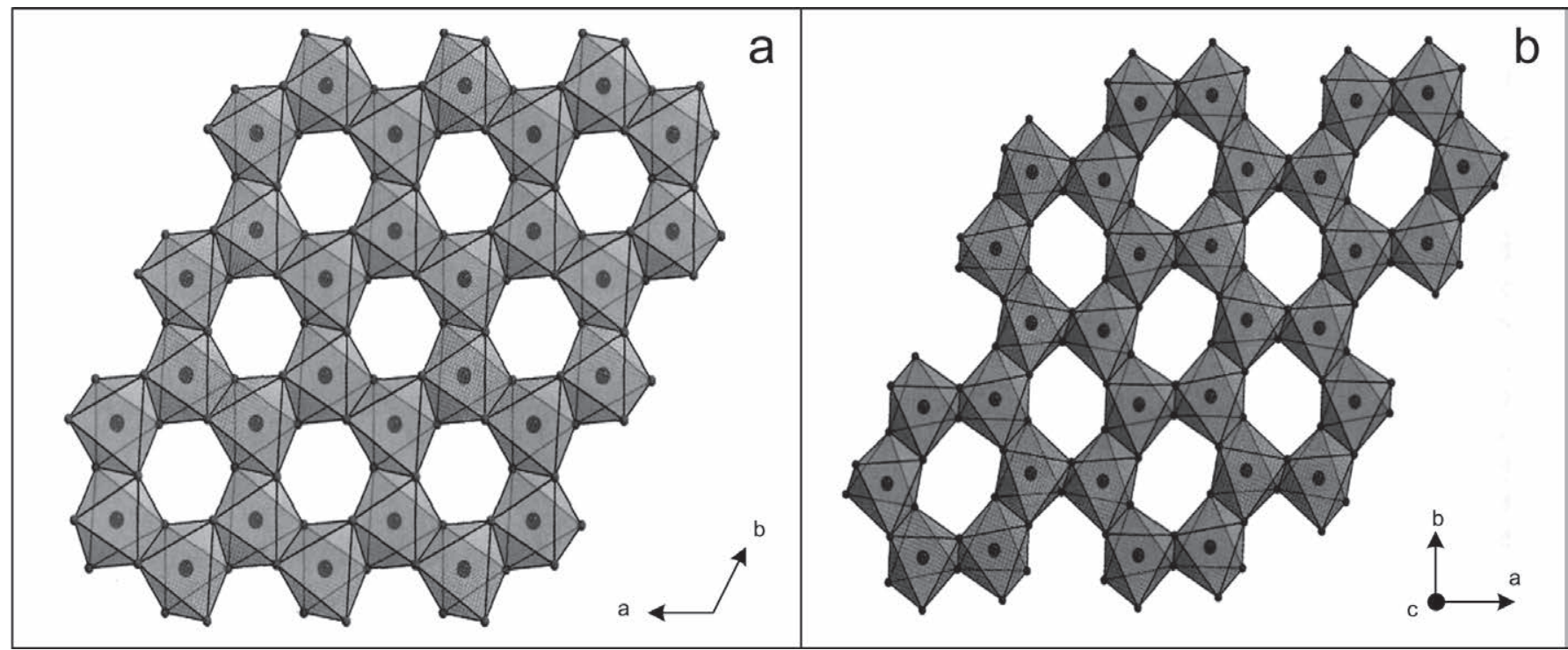

Figura 1 Estructura del corindón $\alpha-\mathrm{Al}_{2} \mathrm{O}_{3}$ (a) y de la gibbsita $\mathrm{Al}(\mathrm{OH})_{3}$ (b) basadas en láminas de octaedros de aluminio coordinado con oxígeno y con grupos hidroxilo respectivamente, que comparten tres aristas.

(54). La posición de los grupos hidroxilos está relacionada no solo con los huecos ocupados por los cationes aluminio sino también con las vacantes catiónicas $(53,55)$.

La $\theta$-alúmina presenta una estructura monoclínica con una mayor proporción de átomos de aluminio ocupando posiciones tetraédricas, en comparación con las alúminas de menor temperatura. Se considera una estructura más ordenada e intermedia entre la tipo espinela de las otras alúminas de transición y la $\alpha$-alúmina $(50,56)$.

En la estructura corindón, esquematizada en la Figura 1a, los aniones ocupan las posiciones de una red hexagonal compacta y dos tercios de los huecos octaédricos están ocupados por los cationes aluminio. La unidad básica de construcción, desde otro punto de vista, es el aluminio en coordinación octaédrica con el oxígeno, formando láminas de anillos hexagonales por compartición de tres aristas que se apilan en el eje c. Esta estructura es semejante a la de la gibbsita, sólo que en ésta el aluminio se encuentra en coordinación con grupos $\mathrm{OH}$, Figura 1b (39).

La deshidratación a temperaturas inferiores a $350-400{ }^{\circ} \mathrm{C}$ de los oxo/hidróxidos más comunes produce un aumento de la superficie específica y de la densidad, como se observa en el gráfico de la Figura 2, consecuencia de la eliminación de agua (57). Es considerada una transformación pseudormórfica hacia la generación de óxido de aluminio $(50,58,59)$ en la que aumenta la porosidad, distinguiéndose en general tres tipos de poros: i) los macroporos, existentes entre las partículas de oxo/hidróxido; ii) poros de deshidratación, procedentes de la propia esfera de hidratación del hidróxido; iii) pequeños poros interpartículares (60). Las diferencias en los mecanismos de deshidratación de los distintos oxo/hidróxidos pueden explicar las diferencias en la textura microporosa de las alúminas generadas tipo espinela y al mismo tiempo sus diferencias cristalográficas (58).

Existe controversia sobre las rutas de transformación entre las diferentes formas de alúmina. En la Figura 3 se muestra la secuencia de transición establecida por Stumpf y col. (61), así como por Tertian y Papée (62), ampliamente aceptada.

Desde un punto de vista cristalográfico, la transición térmica irreversible de las alúminas de transición de baja

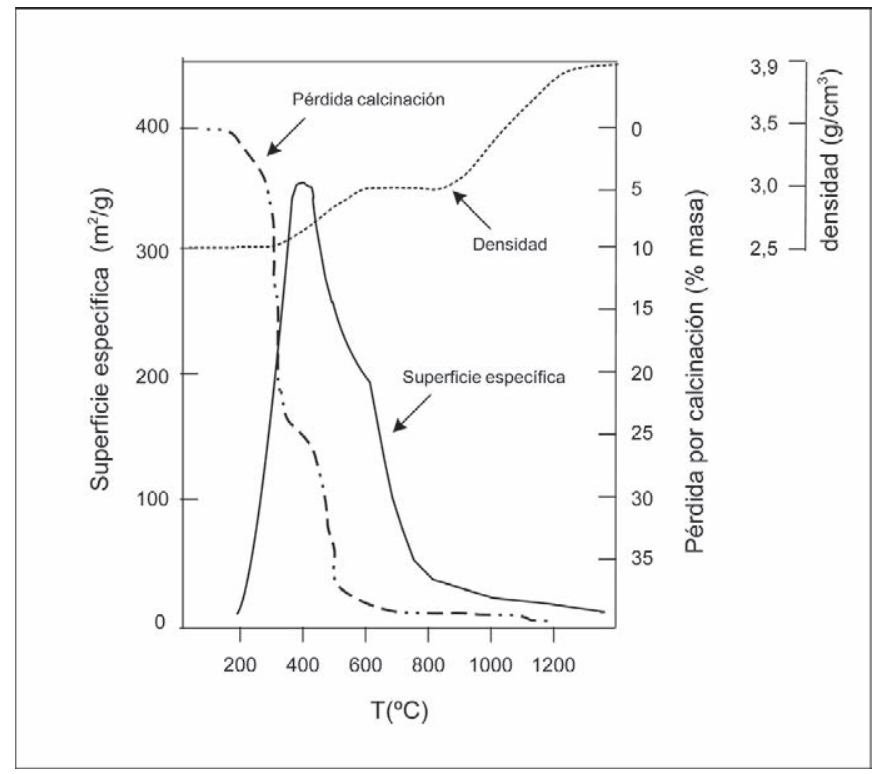

Figura 2. Variación de la superficie específica, masa y densidad de la gibbsita respecto a la temperatura de calcinación. Adaptación de Ref. (57).

temperatura hacia las de alta es un proceso continuo, una mera transición desde fases más desordenas hacia las más ordenadas $(48,49)$. De hecho, las diferencias cristalográficas entre las dos familias de alúminas de transición, como se ha comentado, son relativamente pequeñas y no trascurren con cambios sustanciales de energía $(50,63)$, salvo algún pequeño efecto exotérmico asociado a un mejoramiento cristalino (64). Frecuentemente no se obtiene una única fase a una temperatura dada, sino mezclas de distintas fases debido precisamente a que la transformación es un proceso continuo que implica consideraciones de tipo cinético.

Las transformaciones topotácticas $\gamma \rightarrow \delta \rightarrow \theta$ están acompañadas de cambios en la morfología y porosidad de las alúminas (65), afectando especialmente a la microporosidad $(56,66)$. Desde un punto de vista catalítico, esta transición es crítica, pues las de alta temperatura son menos activas, no 


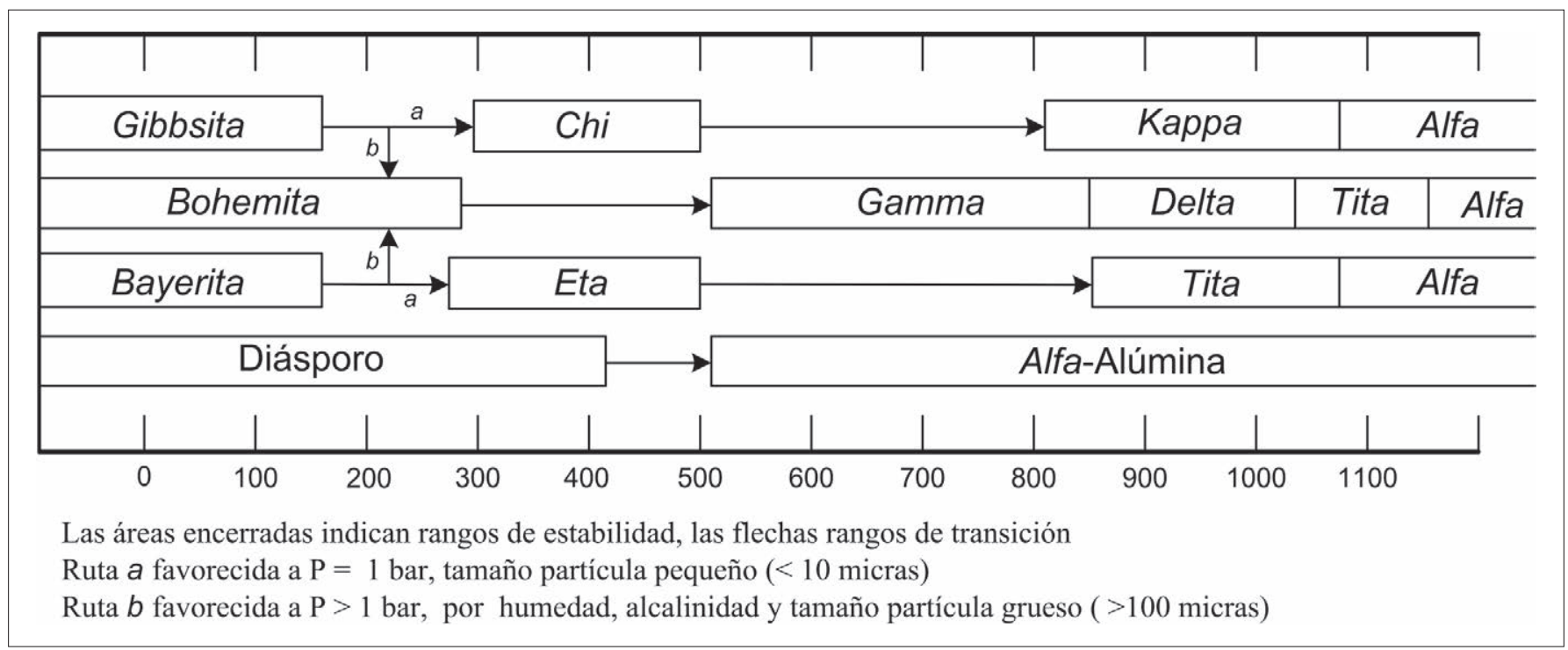

Figura 3. Secuencia de deshidratación de los hidróxidos y óxidos de aluminio en aire.
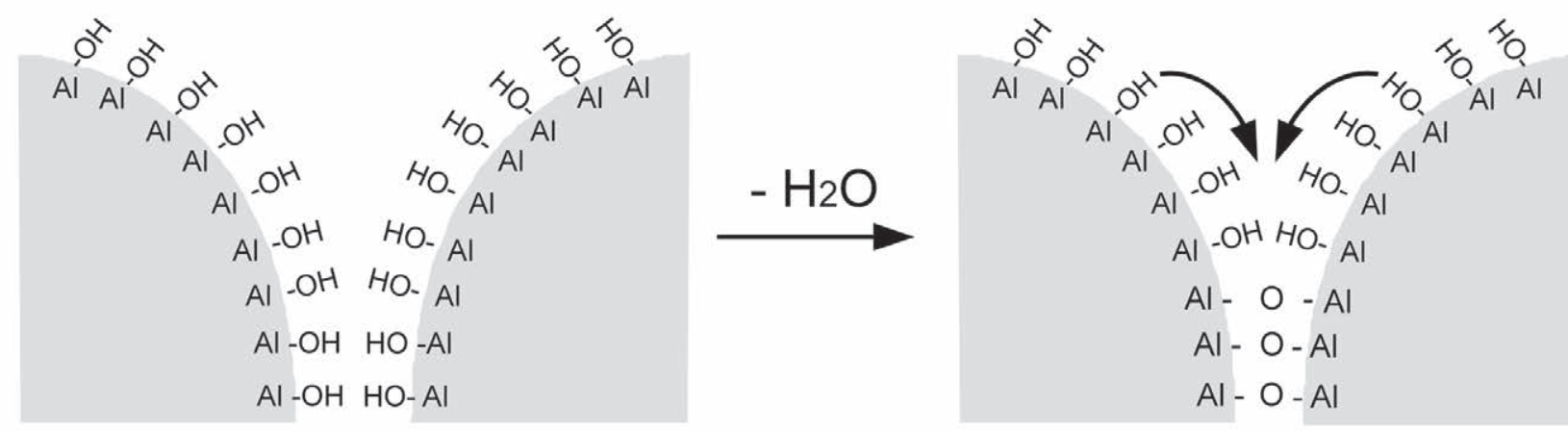

Figura 4. Modelo que representa la deshidroxilación superficial en la región de contacto entre dos partículas adyacentes. Adaptación de Ref. (71).

sólo por una menor superficie específica sino también por una menor proporción de centros activos $(53,67)$. Durante la transformación de fases de los óxidos de aluminio, además de las modificaciones en la red cristalina y en la coordinación del aluminio $(47,68)$, se producen fenómenos de sinterización y crecimiento de grano, acompañado de una disminución de superficie específica (65), así como de un aumento de la densidad (69), reflejada en el gráfico de la Figura 2. La pérdida progresiva de superficie conforme aumenta la temperatura es debida a fenómenos de sinterización, por formación de conexiones entre las partículas consecuencia de efectos difusionales $(70,71)$.

Los fenómenos asociados a la pérdida de grupos hidroxilos explican el proceso de transformación continua entre las distintas fases de transición. Burtin y col. (72) proponen la evolución de las alúminas de transición mediante mecanismos de deshidroxilación por los que aumenta la proporción de vacantes aniónicas. Según su modelo, la estructura $\alpha-\mathrm{Al}_{2} \mathrm{O}_{3}$ se puede representar como $\left[\mathrm{Al}_{2}\right] \square \mathrm{O}_{3-\mathrm{V} / 2}(\mathrm{OH})_{\mathrm{V}} \diamond_{1-\mathrm{V} / 2^{\prime}}$ donde [Al] representa los cationes aluminio en sitios trivalentes, $\square$ las vacantes catiónicas en sitios divalentes, $(\mathrm{OH})$ los grupos hidroxilo que sustituyen al oxígeno en las posiciones aniónicas de la red y $\diamond$ las vacantes aniónicas de una estructura espinela. Este modelo describe la secuencia de transformación bohemita $\rightarrow \gamma \rightarrow \theta \rightarrow \alpha$ por pérdida de grupos hidroxilos. Si $\mathrm{V}=2$, la fórmula se reduce a la estequiométrica de la bohemita, $\left[\mathrm{Al}_{2}\right]$ $\square \mathrm{O}_{2}(\mathrm{OH})_{2}$. Si $\mathrm{V}=0$, se reduce a la de la fase $\alpha-\mathrm{Al}_{2} \mathrm{O}_{3^{\prime}}\left[\mathrm{Al}_{2}\right]$ $\square \mathrm{O}_{3} \diamond$. La deshidroxilación, $\mathrm{V} \rightarrow 0$, puede expresarse como

$$
2(\mathrm{OH}) \rightarrow \mathrm{H}_{2} \mathrm{O}+\mathrm{O}+\diamond
$$

Puesto que existen vacantes catiónicas en la red, la anulación de las mismas con las vacantes aniónicas creadas conduce a la destrucción de la estructura espinela, provocando una reorganización estructural con liberación de energía. Según este modelo, la transformación final $\theta \rightarrow \alpha$ se produce gracias a la combinación de vacantes aniónicas y catiónicas,

$$
\square+\diamond \rightarrow 0
$$

El modelo de crecimiento de partícula en las alúminas de transición propuesto por Johnson (73) también tiene en cuenta los fenómenos de deshidroxilación. Según éste, el crecimiento se produce por generación de enlaces Al-O-Al entre dos partículas adyacentes, próximas al contacto, debido a la recombinación de grupos -OH superficiales, con la consiguiente liberación de agua, como se esquematiza en la Figura 4.

La velocidad de pérdida de superficie específica, además de seguir una relación tipo Arrhenius con la temperatura, 
depende de la propia área superficial de la alúmina y resulta proporcional a la presión de vapor del medio (73). El vapor de agua tiene un efecto constatado en la sinterización de los adsorbentes y catalizadores como la alúmina, sin embargo el mecanismo no está esclarecido (74). La aceleración de la sinterización depende de la proximidad entre partículas, por lo que la morfología y tamaño de las mismas juegan un papel importante, así como también la presencia de vapor de agua, al facilitar la generación de puentes intrapartícula. La función de los grupos hidroxilos a este respecto es doble, pues también cabe la posibilidad de que su presencia promueva la difusión de grupos hidroxilos estructurales y la generación de vacantes catiónicas en la red de óxido de aluminio, favoreciendo la anulación de vacantes y la transformación de fase según el mecanismo propuesto por Pijolat y col. $(75,76)$.

La transformación hacia alfa-alúmina es un paso crítico. Desde el punto de vista cristalográfico implica un reordenamiento estructural de los átomos de oxígeno, acompañada de liberación de energía. El mecanismo por el que transcurre la transformación ha sido ampliamente estudiado pero no se ha establecido de forma clara. Según Badkar y Bailey (77) la transformación de fase $\theta \rightarrow \alpha$ involucra mecanismos de nucleación y crecimiento de la fase más estable sobre el manto cristalino de $\theta-\mathrm{Al}_{2} \mathrm{O}_{3}$. Concluyen además que debido a esta transformación y a la reestructuración de poros asociada, la sinterización y densificación de la alúmina resulta ralentizada. Algunos autores indican que la nucleación de alfa se debe a los esfuerzos de compresión que se generan en la red cristalina (78). Una observación diferente, anterior a la investigación de Badkar y Bailey, es la realizada por Iler (79), quien detectó la nucleación de $\alpha-\mathrm{Al}_{2} \mathrm{O}_{3}$ sobre un lecho amorfo, llegando a la conclusión de dicha fase vítrea debía consistir en la alúmina, procedente de los cristales menguantes de $\theta-\mathrm{Al}_{2} \mathrm{O}_{3^{\prime}}$ que está en proceso de transformación. En esta misma línea, Tucker y Bleier (80) demostraron que la transformación a fase alfa comienza en las regiones o cuellos de sinterización. También Schaper y col. (70) concluyen que la nucleación de $\alpha-\mathrm{Al}_{2} \mathrm{O}_{3}$, precedida de los fenómenos de sinterización que provocan la disminución de energía superficial y la estabilidad del sistema, tiene lugar en los cuellos de sinterización, por encontrarse en ellos una mayor proporción de defectos y dislocaciones estructurales. En dichas zonas, la generación de vacantes aniónicas generadas por la propia deshidroxilación resulta consistente con la nucleación de alfa-alúmina por anulación con las vacantes catiónicas según la ecuación [2].

En general estas observaciones han generado dos formas distintas de entender la nucleación de la fase alfa: i) según el mecanismo de deslizamiento de planos cristalinos "sincrocizalla" (syncro-shear) y ii) según el mecanismo difusional. El primero sugiere que las cristalitas de $\theta-\mathrm{Al}_{2} \mathrm{O}_{3}$ sinterizan hasta un tamaño critico de cluster o aglomerado, momento en el que se produce la transformación a alfa por el desplazamiento tangencial de las capas de oxígeno $(81,82)$. Sin embargo, el estudio de Bagwell y col. (83) concluye que la nucleación de fase alfa no requiere de un tamaño crítico de alúmina de transición, siendo éste el resultado del tiempo de inducción necesario para generar núcleos alfa detectables por las técnicas empleadas. Otras observaciones que apoyan el mecanismo de difusión derivan de los efectos que la siembra tiene en la disminución de temperatura de formación de $\alpha-\mathrm{Al}_{2} \mathrm{O}_{3}$, al generar sitios de menor energía superficial $(84,85)$.
Según el esquema de la Figura 3, la temperatura de formación de alfa-alúmina oscila entre $1100-1150{ }^{\circ} \mathrm{C}$, aunque otros autores la han establecido entre $1200-1300{ }^{\circ} \mathrm{C}(64,86)$. La temperatura de generación de $\alpha-\mathrm{Al}_{2} \mathrm{O}_{3}$ es función de los reactivos iniciales, del tamaño de partícula, de las impurezas y de los agentes mineralizadores que se añadan. Numerosas investigaciones constatan que partiendo de diásporo se consiguen las temperaturas más bajas de transformación a fase alfa. La explicación reside en la transformación directa topotáctica diásporo $\rightarrow \alpha-\mathrm{Al}_{2} \mathrm{O}_{3}$, favorecida por el hecho de que ambas fases tienen una estructura semejante de átomos de oxígeno localizados en una red hexagonal compacta (87, 88). Diferentes prácticas permiten rebajar la temperatura de formación de fase alfa, como la siembra con cristales de $\alpha-\mathrm{Al}_{2} \mathrm{O}_{3}$ ya comentada, la síntesis por métodos termales $(89,90)$, la molienda del material de partida o síntesis mecanoquímica (91-93), la presencia de vapor de agua durante el tratamiento térmico $(85,94,95)$, el empleo de precursores de aluminio tipo carboxilato (96) y la adición de sacarosa en la solución precursora (97-99).

\section{OBTENCIÓN DE ALÚMINA}

Los métodos habituales de obtención de alúmina con fines cerámicos, $\alpha-\mathrm{Al}_{2} \mathrm{O}_{3}$, consisten en la calcinación de hidróxidos de aluminio, alúminas de transición o sales de aluminio, así como la solidificación a partir de fundidos. El método comercial más empleado es la calcinación del hidróxido de aluminio obtenido a través del proceso Bayer, a través de la hidrólisis del aluminato sódico (42b):

\section{Bauxita $\left(\mathrm{Al}_{2} \mathrm{O}_{3}-\mathrm{H}_{2} \mathrm{O}\right)+2 \mathrm{NaOH} \rightarrow$}

$\rightarrow$ Aluminato sódico $\left(\mathrm{Na}_{2} \mathrm{O} \cdot \mathrm{Al}_{2} \mathrm{O}_{3}\right)+4 \mathrm{H}_{2} \mathrm{O}+$ "barros rojos" [3] Aluminato sódico $\left(\mathrm{Na}_{2} \mathrm{O} \cdot \mathrm{Al}_{2} \mathrm{O}_{3}\right)+4 \mathrm{H}_{2} \mathrm{O}+$ Semillas $\mathrm{Al}(\mathrm{OH})_{3} \rightarrow$ $\rightarrow \mathrm{Al}(\mathrm{OH})_{3}+2 \mathrm{NaOH}$

Las diferentes categorías comerciales de óxido de aluminio se diferencian en el tamaño de partícula, morfología, contenido en $\alpha-\mathrm{Al}_{2} \mathrm{O}_{3}$, superficie específica e impurezas, agrupándose en distintos tipos según el método de obtención y las características propias, distinguiéndose fundamentalmente las alúminas calcinadas, tabulares y fundidas (100). Todas ellas son alúminas densas al presentar un alto contenido en fase alfa (> $75 \%$ ), con cristales de tamaño comprendido entre 50-500 $\mu \mathrm{m}$, llegando a superar el milímetro en el caso de las fundidas. Las impurezas más comunes en $\%$ masa son $\mathrm{Na}_{2} \mathrm{O}(0.2-0.6 \%), \mathrm{SiO}_{2}(0.02$ $0.06 \%)$ y $\mathrm{Fe}_{2} \mathrm{O}_{3}(0.02-0.06 \%)$, porcentajes que difieren en los corindones obtenidos por fusión, en los que aumenta el $\mathrm{Fe}_{2} \mathrm{O}_{3}$ $(<0.3 \%)$, llegando a presentar $\mathrm{TiO}_{2}(1.4-2.70 \%)$ si el corindón se prepara por fusión directa de bauxita (corindón marrón).

La obtención de alúminas especiales, con bajo contenido en sodio $(<0.1 \%$ masa) y alúminas de alta pureza, $>99.99 \%$ en $\mathrm{Al}_{2} \mathrm{O}_{3}$, requiere la adición de agentes $\left(\mathrm{Cl}_{2}, \mathrm{AlF}_{3}\right.$ gas) durante la calcinación, o un lavado posterior con ácido clorhídrico, o bien de etapas auxiliares de recristalización y/o purificación con resinas intercambiadoras (42c). Los óxidos de aluminio de muy alta pureza se obtienen, a menor escala y de forma más costosa a través de métodos específicos, según el campo de aplicación al que vayan destinados, como la técnica sol-gel, la síntesis hidrotermal, la descomposición térmica de sales de aluminio, la oxidación de aluminio y la deposición química en fase vapor (CVD). 


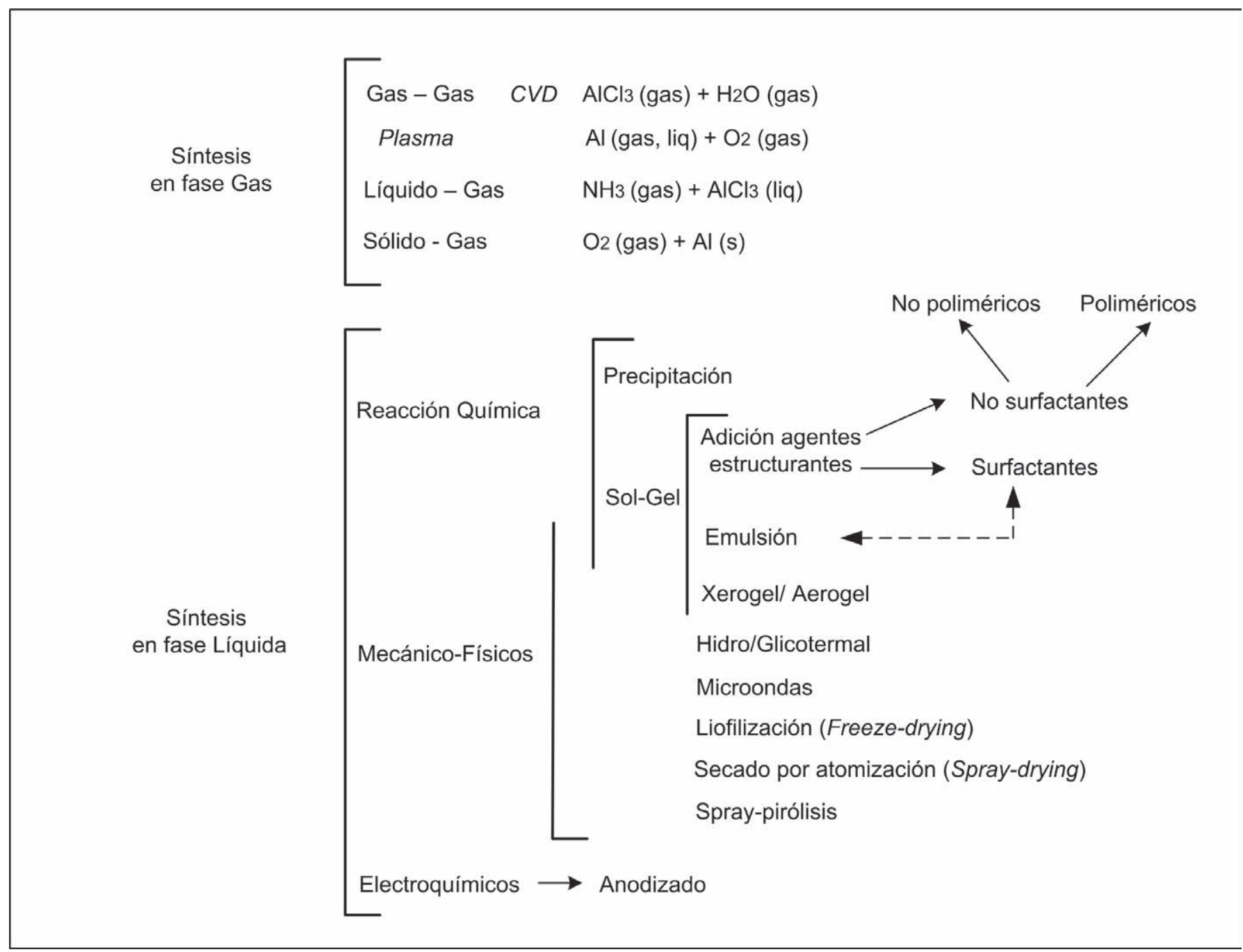

Figura 5 Clasificación de diferentes rutas de síntesis de alúmina.

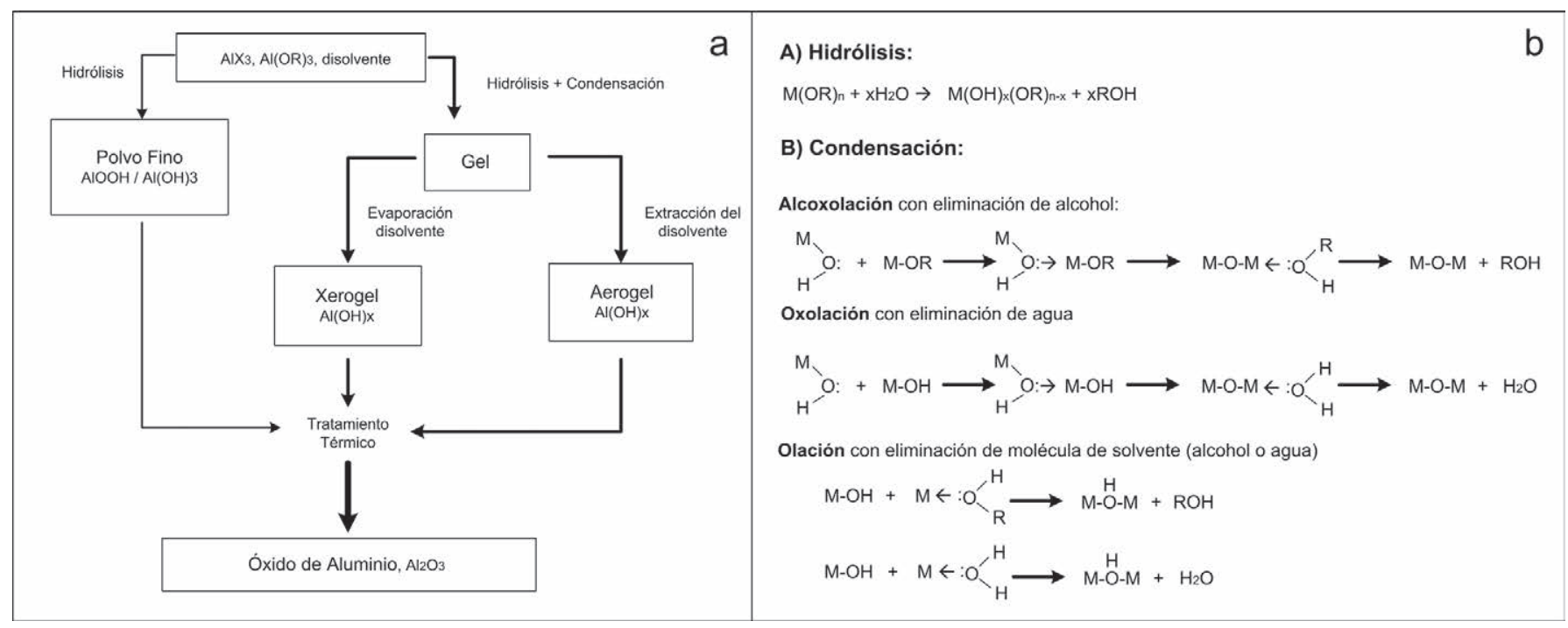

Figura 6 Diagrama de flujo para la obtención de alúmina mediante ruta sol-gel (a). Reacciones de hidrólisis y condensación para un alcóxido metálico, M(OR)n (b) Adaptación de Ref. (130).

La Figura 5 muestra una clasificación general de diferentes métodos de síntesis de alúmina según sea obtenida por reacción en fase gas (a través de la reacción de solución acuosa $\mathrm{AlCl}_{3}$ con $\mathrm{NH}_{3}$ gaseoso (101), por plasma térmico (102), oxidación de aluminio $(103,104)$ o CVD (105) entre otros) o por reacción en fase líquida (tanto acuosa como no acuosa). En este último caso se distinguen aquellas rutas basadas en reacciones químicas para la generación del hidróxido u oxido de aluminio, de otras en las que además intervienen métodos mecánico-físicos para la texturización de la alúmina 
(xerogel/aerogel (106), emulsión-evaporación (107-109), tratamiento termal $(90,110,111)$, microondas (112), secado por atomización (113), liofilización (114), spray-pirólisis (115)) o basadas en procesos electroquímicos, como el anodizado de aluminio $(116,117)$.

La gran mayoría de rutas sintéticas de alúmina que utilizan el hidróxido de aluminio como agente precursor se asientan sobre los métodos de precipitación y de sol-gel.

Los primeros se basan en reacciones de hidrólisis en medio acuoso, por reacción de una sal de aluminio $\left(\mathrm{AlCl}_{3^{\prime}}\right.$, $\left.\mathrm{Al}_{2}\left(\mathrm{SO}_{4}\right)_{3}, \mathrm{Al}\left(\mathrm{NO}_{3}\right)_{3}, \mathrm{NH}_{4} \mathrm{Al}\left(\mathrm{SO}_{4}\right)_{2}\right)$ con una base $(\mathrm{NaOH}$, urea, $\mathrm{NH}_{4} \mathrm{OH}$, formamida, $\mathrm{Na}_{2} \mathrm{CO}_{3^{\prime}} \mathrm{NaHCO}_{3^{\prime}}\left(\mathrm{NH}_{4}\right)_{2} \mathrm{CO}_{3^{\prime}} \mathrm{NH}_{4} \mathrm{HCO}_{3^{\prime}}$ hexametilentetramina entre otras) (118-121) o por simple aumento de temperatura y envejecimiento de disoluciones ácidas de aluminio (122).

La metodología sol-gel, esquematizada en la Figura 6a, ha sido ampliamente utilizada en la síntesis de alúminas porosas por ser una técnica sencilla y versátil que emplea sales de aluminio (ruta sol-gel coloidal) (123-125) o alcóxidos de aluminio (ruta sol-gel polimérica) (126-128) con objeto de conseguir una mayor pureza, siendo muy seguida la ruta propuesta por Yoldas (129). Las principales reacciones involucradas son la hidrólisis (formación de un sol), por la que se obtienen especies $\mathrm{Al}-\mathrm{OH}$ reactivas, y la condensación de las mismas, formando especies - Al-O-Al- según las reacciones simplificadas mostradas en la Figura 6 b (130), generando geles coloidales (translucidos/opacos) y poliméricos (transparentes), según la reacción general

$$
\mathrm{Al}(\mathrm{OR}) \mathrm{n}+\mathrm{n} \mathrm{H}_{2} \mathrm{O} \rightarrow \mathrm{Al}(\mathrm{OH}) \mathrm{n}+\mathrm{n} \mathrm{ROH}
$$

Tras el secado y eliminación del disolvente se produce hidróxido de aluminio cuya calcinación originará un óxido de alúmina muy puro.

La extensión de las reacciones de hidrólisis y condensación (alcoxolación, oxolación, olación), el tipo de precursor empleado y los parámetros del proceso sol-gel (relación agua/ alcóxido, concentraciones, disolvente, agentes peptizantes, temperatura, velocidad y tiempo de mezcla, tiempo de envejecimiento y condiciones de secado entre otras variables) configuran la morfología y estructura del óxido de aluminio resultante (131).

Lejos de ser una reacción simple, la hidrólisis del aluminio tanto de alcóxidos como de sales inorgánicas genera, en función de las condiciones y parámetros del proceso, diferentes especies hidrolizadas de aluminio, mononucleares y poliméricas, responsables del transcurso del proceso de gelificación (123, 132-136).

\section{SÍNTESIS DE ALÚMINA POROSA}

En la siguiente descripción se emplea la tipificación de materiales porosos establecida por la IUPAC (137), realizada en base al diámetro de poro, que distingue materiales microporosos (aquel con poros inferiores a $2 \mathrm{~nm}$ ), mesoporosos (con poros entre 2 - $50 \mathrm{~nm}$ ) y macroporosos (tamaño superiores a $50 \mathrm{~nm}$ ).

\subsection{Síntesis de alúmina activada}

Las alúminas de transición, conocidas en general como gamma-alúminas o alúminas activadas (100), son las que se vienen utilizando para los fines anteriormente comentados, por ofrecer una alta superficie específica, entre 150 - 400 $\mathrm{m}^{2} / \mathrm{g}$, además de presentar centros activos tipo ácido de Lewis y Brönsted (21, 138, 139). Sin embargo, la disminución de superficie específica consecuencia del aumento de la temperatura es uno de los principales inconvenientes. Los procesos de sinterización y transformación de fases limitan la temperatura y tiempo de uso, no sólo durante el proceso en sí mismo, sino también durante su regeneración.

Existen diferentes estrategias para aumentar la estabilidad térmica de estas alúminas, entre las que destaca la introducción de aditivos que reduzcan la sinterización por diferentes mecanismos, como por ejemplo dificultando la difusión (por disminución de vacantes catiónicas, generación de compuestos en los bordes de cristalita/grano) o disminuyendo los grupos hidroxilo en superficie. El efecto de la adición de distintos óxidos, como $\mathrm{SiO}_{2}$ y de cationes como $\mathrm{La}^{3+}, \mathrm{Ce}^{4+}, \mathrm{Zr}^{4+}$, $\mathrm{Th}^{4+}, \mathrm{Ca}^{2+}, \mathrm{Mg}^{2+}, \mathrm{Ga}^{3+}, \mathrm{In}^{3+}$ entre otros, ha sido ampliamente estudiado en las alúminas (72 73, 140-144) sin embargo, la diversidad de parámetros implicados dificulta el consenso entre diversos autores $(71,145)$. Otras tácticas se basan en el control de la morfología de las partículas de óxido de aluminio con objeto de disminuir las zonas de interacción entre las mismas $(146,147)$.

La diversidad de aplicaciones industriales ha hecho que el control morfológico y textural de las alúminas se convierta en un campo de investigación muy activo (148-152).

En los soportes de alúmina preparados por deshidroxilación directa de los precursores oxo/hidróxidos bien cristalizados (gibbsita, bayerita, bohemita), otro de los principales inconvenientes es la generación de una elevada proporción de poros estrechos. Estos dificultan los procesos de penetración y difusión de los agentes catalizadores activos, impidiendo un recubrimiento homogéneo y efectivo de la superficie. El empleo de hidróxidos de aluminio amorfos o mal cristalizados (alúmina gel, pseudo-bohemita) generan poros más anchos evitando problemas asociados a la difusión (153). Se han realizado numerosas investigaciones relativas al control de la distribución del tamaño de poro, regulando el tamaño de partícula/aglomerado (digestión o envejecimiento, peptización) y/o empleando aditivos generadores de porosidad. Una completa revisión bibliográfica al respecto es la realizada por Trimm y Stanislaus (154).

En general, las rutas empleadas para la síntesis de alúminas mesoporosas de alta superficie y con una estructura de poros estrecha se encuadran según dos tipos de enfoques distintos, descritos por Schüth (155) para la síntesis de materiales inorgánicos porosos: endo-máscara (endotemplating) y exomáscara (exotemplating). El primero emplea moléculas y el segundo máscaras rígidas para la generación de estructuras porosas, como se esquematiza en la Figura 7a.

El uso de moléculas o agentes estructuro-directores (ácidos carboxílicos, tensoactivos, copolímeros) es uno de los métodos de generación de porosidad controlada en las alúminas más estudiados, ampliamente revisado por Márquez-Álvarez y col. (156). Fundamentalmente se trata de gamma-alúminas, con superficies comprendidas entre $100-800 \mathrm{~m}^{2} / \mathrm{g}$, sintetizadas en un rango de temperaturas $300-900{ }^{\circ} \mathrm{C}$, y con una distribución de poros muy estrecha, prácticamente monomodal, en torno a 15 - 150 Å de diámetro. Las alúminas generadas por esta vía se suelen denominar genéricamente OMA (Organized Mesoporous Alumina). 


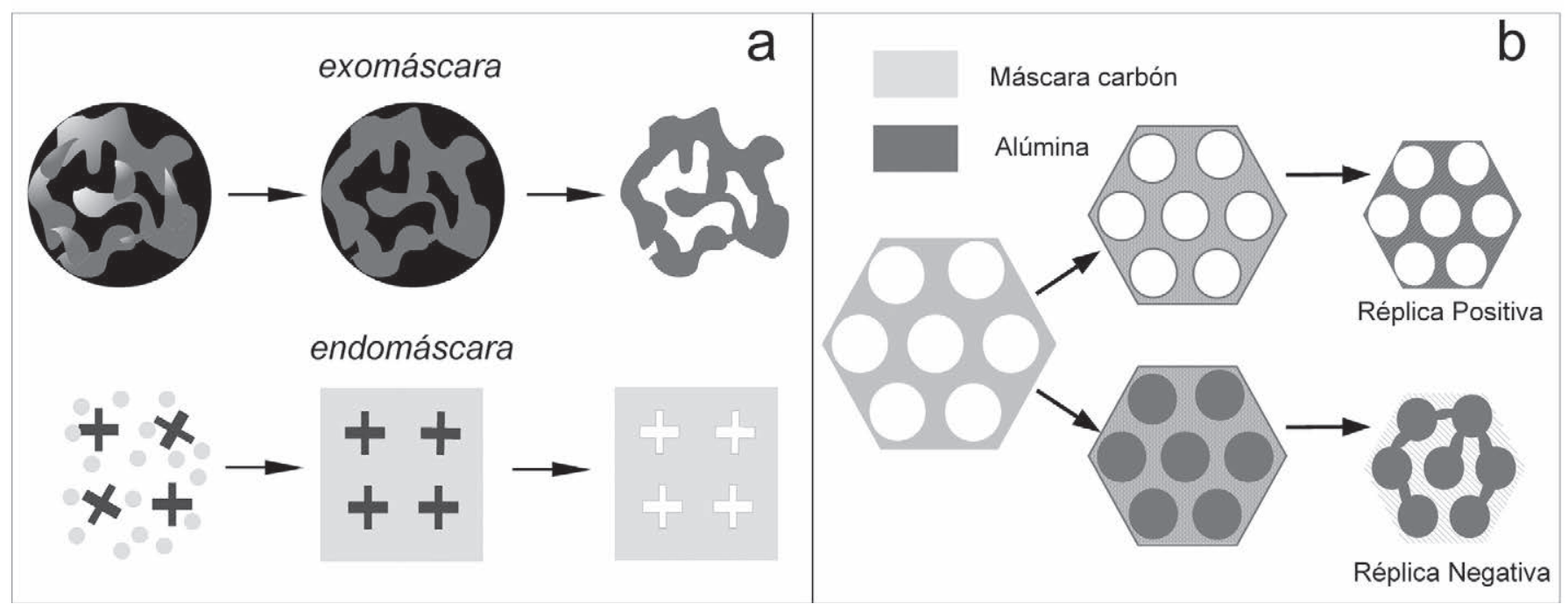

Figura 7 Representaciones esquemáticas de los métodos endo y exo-máscara (a) y de réplica positiva y negativa de máscaras carbonosas (b). Adaptaciones de Refs. (155) y (157) respectivamente.

Más recientemente seestá empleandola técnica denominada nanocasting para generar alúminas estructuralmente ordenadas (156), recubriendo estructuras mesoporosas de carbón con el precursor de alúmina. Estas estructuras carbonosas consisten en carbón activado o en estructuras OMC (Ordered Mesoporous Carbon), generadas a partir de otras de sílica denominadas OMS (Ordered Mesoporous Silica) (155). La calcinación posterior de la máscara carbonosa produce réplicas cerámicas de óxido de aluminio, bien réplicas positivas o negativas, conocidas también como OCAMS (Ordered Crystalline Alumina Molecular Sieves), esquematizadas en la Figura $\mathbf{7 b}$. Las gamma-alúminas obtenidas tras la combustión de la estructura de carbón aproximadamente a $600{ }^{\circ} \mathrm{C}$, presentan una elevada superficie específica, entre $150-400 \mathrm{~m}^{2} / \mathrm{g}$ y una distribución de microporos estrecha, centrados en torno a $4-7 \mathrm{~nm}$. Wu y col. (157) indican que al aumentar la temperatura de combustión a $900{ }^{\circ} \mathrm{C}$, aún manteniéndose como fase mayoritaria la gamma, la superficie decae hasta $80 \mathrm{~m}^{2} / \mathrm{g}$ debido a fenómenos de sinterización y crecimiento de partícula, en torno a 8 - $9 \mathrm{~nm}$, conducentes a una pequeña fracción de alfa-alúmina. Liu y col. (158) también señalan que la combustión a $1000{ }^{\circ} \mathrm{C}$ produce una mezcla de fases $\gamma+\delta$, generando una menor superficie y un mayor tamaño medio de poro, $90 \mathrm{~m}^{2} / \mathrm{g}$ y $10 \mathrm{~nm}$.

El empleo de alúminas macroporosas resulta interesante en sistemas proclives a la obstrucción del adsorbente o desactivación del catalizador, tales como filtros, membranas y lechos catalíticos. Sin embargo, debido a su baja superficie específica, su uso se suele limitar a pretratamientos previos de proceso, menos selectivos y específicos, siendo necesarias etapas adicionales en las que intervengan alúminas activadas. La utilización de estas últimas requiere a su vez de soportes macroporosos donde quedan dispersas, para así favorecer la difusión de reactivos y productos, y al mismo tiempo facilitar su manipulación.

La extrusión o prensado de polvo de alúmina (o de sus precursores oxo/hidróxidos) con agentes generadores de porosidad, tales como negro de carbón, coque de petróleo o melamina, ha sido una de las formas más habituales para crear macroporos una vez eliminado por combustión los elementos de relleno (154). La síntesis de cerámicas con morfología celular (réplicas, esponjas, panales de abeja,

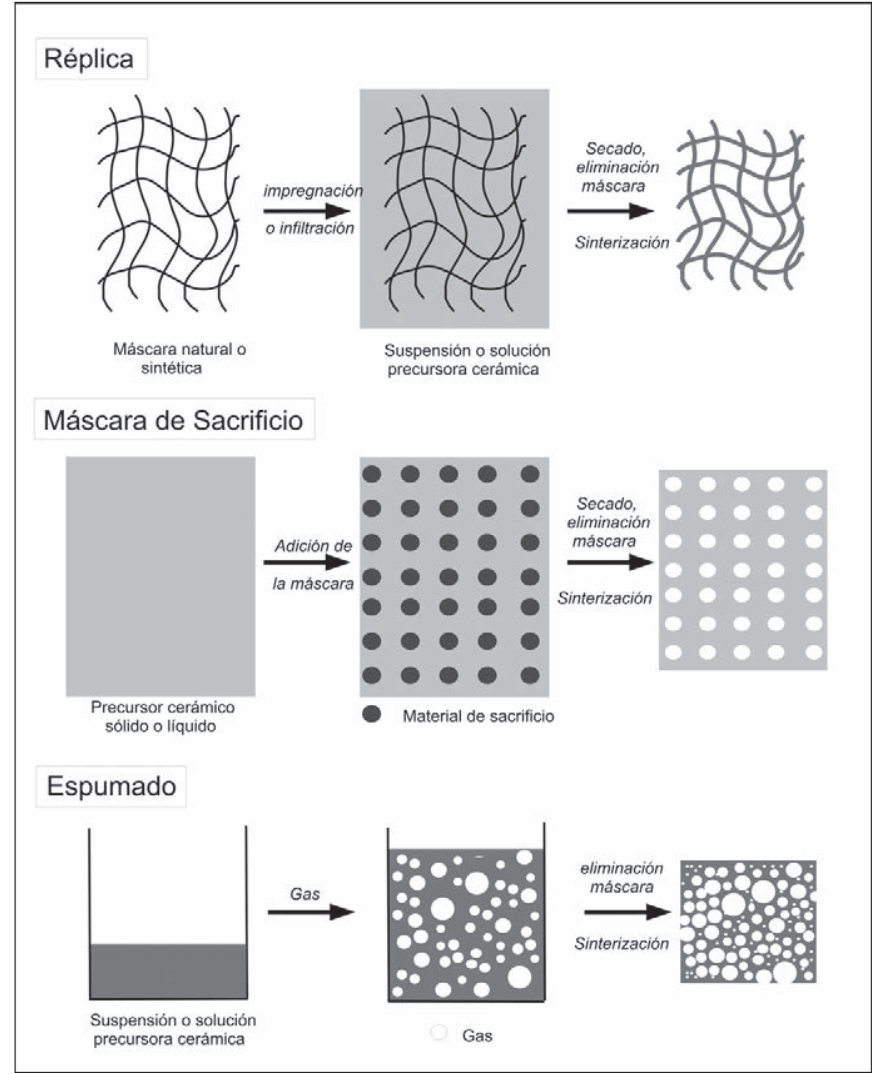

Figura 8 Esquematización de diferentes rutas de procesado para la síntesis de cerámicas macroporosas. Adaptación de Ref. (158).

interconexión de filamentos, fusión de esferas huecas, etc.) ha abierto nuevas rutas de generación de macroporosidad controlada, bien mediante el uso de agentes o máscaras precursoras de poros, en combinación con / o bien a través del conformado de la estructura mediante técnicas de espumado, extrusión o prototipado robotizado entre otras (159-168). En la Figura 8 se esquematizan las principales diferencias entre tres metodologías de generación de macroporos: infiltración o réplica, máscara de sacrificio y espumado. En concreto, las técnicas de réplica que utilizan máscaras naturales, en especial las de tipo lignocelulósico, han suscitado gran interés en 
la última década para fabricar no sólo cerámicas celulares macroporosas, sino también estructuras con un entramado de poros específico función de la máscara seleccionada, como se comenta con más detalle en el último apartado.

Actualmente la síntesis de alúminas dotadas de una estructura jerárquica de poros, conocidas como HOMA (Hierarchically Ordered Mesopores and Macropores Alumina), es la que acapara una mayor atención $(16,169-172)$ debido a la mayor eficacia en los fenómenos de transporte y difusión, tanto de reactivos como de productos, al existir una interconectividad de poros de diferente tamaño. La síntesis de estructuras con jerarquía de poro controlada se puede realizar combinando distintos métodos de generación de mesoporos y macroporos $(3,4)$ brevemente comentados ya. La generación de alúminas con jerarquía de poro controlada se ha venido realizando a través de diferentes métodos, como tratamiento hidrotermal $(16,173)$, empleo de tensoactivos mixtos (iónicos - neutros) (169), tensoactivos más aditivos orgánicos (172), surfactantes y condiciones hidrodinámicas (174), así como también a través del empleo de distintas mascaras, como espumas o cristales coloidales $(171,175,176)$.

En cualquier caso, la mayoría de los métodos empleados en la síntesis de alúminas mesoporosas jerárquicas o estructuralmente ordenadas suelen implicar el uso de costosos precursores generadores de porosidad, para finalmente ser eliminados en una etapa de extracción o de calcinación. Es por ello que la técnica de bio-réplica que emplea máscaras naturales, comentada posteriormente, presenta un interés renovado.

\subsection{Síntesis de alfa-alúmina de elevada superficie específica}

Numerosas investigaciones han tenido como fin la síntesis de alfa-alúmina con alta superficie específica, con objeto de aprovechar en diferentes campos de aplicación la estabilidad y la resistencia físico-química intrínsecas a dicha fase.

Mediante diferentes tácticas se han conseguido superficies equiparables o considerablemente superiores a las obtenidas por los métodos tradicionales de síntesis de alfa-alúmina, como por ejemplo disminuir la temperatura de transformación hacia la fase estable. Como se ha comentado anteriormente, el empleo de diásporo natural o sintético como precursor permite la generación de $\alpha-\mathrm{Al}_{2} \mathrm{O}_{3}$ a temperaturas inferiores a $500{ }^{\circ} \mathrm{C}$, llegando a obtener superficies entre $40-170 \mathrm{~m}^{2} / \mathrm{g}$. Mitchell (177) describió un procedimiento para obtener alfaalúmina de $168 \mathrm{~m}^{2} / \mathrm{g}$ a partir de un tipo de diásporo natural impuro, calentándolo a $300{ }^{\circ} \mathrm{C}$ durante un largo periodo de tiempo a vacío. La escasez de este mineral natural hace que esta ruta no sea económicamente viable a gran escala, sin embargo, la síntesis de diásporo por métodos hidrotermales resuelve, en parte, este inconveniente $(88,178,179)$.

Otro método consiste en la activación mecánica de gammaalúmina, que permite la transformación instantánea a fase alfa con un aumento considerable de superficie específica $\left(25-100 \mathrm{~m}^{2} / \mathrm{g}\right)$, pero el producto resultante puede consistir en una mezcla de fases de alúmina, además de producir una aglomeración de partículas en función de los distintos parámetros de la molienda (energía de impacto, tiempo de tratamiento, atmósfera, etc.), que va en detrimento de la superficie $(180,181)$.

La alfa-alúmina nanocristalina, sintetizada con objeto de mejorar las propiedades mecánicas de cuerpos cerámicos densos, también presenta una elevada superficie específica. Ésta se puede obtener a través de muy diferentes rutas y tecnologías. Por ejemplo, mediante molienda intensa de alúmina previamente sinterizada y en presencia de agentes que prevengan la agregación se ha alcanzado un tamaño de cristalita en torno a $26 \mathrm{~nm}$ y superficies específicas de 57 $\mathrm{m}^{2} / \mathrm{g}$ (182). A través de la adición de sacarosa a una solución de nitrato de aluminio se ha conseguido sintetizar, tras combustión a $600{ }^{\circ} \mathrm{C}$, nanopartículas de alfa-alúmina en torno a $20 \mathrm{~nm}$, con una superficie superior a $190 \mathrm{~m}^{2} / \mathrm{g}$ y un diámetro de poro entre 18 - $25 \mathrm{~nm}$ (97). Una variante de este método es la introducida por Wang y col. (98). Estos autores, mediante precursores de pseudobohemita/sacarosa, y a través de una etapa previa de pirólisis a $600{ }^{\circ} \mathrm{C}$ durante 4 h, y tras combustión a $800{ }^{\circ} \mathrm{C}$, obtienen alúmina submicrométrica con superficies específicas que oscilan entre $43-67 \mathrm{~m}^{2} / \mathrm{g}$ para mezclas $\alpha+$ $\theta$, resultando una menor superficie en las que transforman completamente a $\alpha-\mathrm{Al}_{2} \mathrm{O}_{3^{\prime}}$ entre $9-16 \mathrm{~m}^{2} / \mathrm{g}$.

No obstante, el rango de estabilidad en los casos comentados estará limitado a bajas temperaturas para evitar así el crecimiento cristalino y la reducción drástica de superficie.

La bibliografía referente a la síntesis de alfa-alúmina con alta superficie específica a temperaturas relativamente elevadas $\left(>1100{ }^{\circ} \mathrm{C}\right)$ está dispersa en multitud de investigaciones de diverso propósito o está sujeta a diferentes patentes, fundamentalmente relacionadas con su aplicabilidad como soporte catalizador en la industria del petróleo (183-185). Cuando el precursor de partida es un oxo/hidróxido o una alúmina de transición y la transformación hacia fase alfa se consigue a través del aumento de temperatura, las tácticas que siguen las diferentes rutas investigadas y los procedimientos patentados se basan en i) el control de la geometría y morfología de partícula en la suspensión/gel, dificultado el contacto entre las mismas, así como en ii) la adicción de agentes y / o precursores que eviten los fenómenos de difusión y sinterización que acompañan a la transformación de fases, además de actuar como agentes combustibles generadores de porosidad.

Sin embargo, en muchas ocasiones la transformación a fase alfa no se produce de forma completa. Así por ejemplo, Elaloui y col. (106) sintetizan alúminas de elevada superficie tras calcinación a $1200{ }^{\circ} \mathrm{C}$ durante 5 horas de aerogeles preparados a partir de secbutóxido de aluminio, utilizando como disolvente agua e isobutanol, consiguiendo alúminas finales con superficies de 33 y $70 \mathrm{~m}^{2} / \mathrm{g}$, consistentes en mezclas de $\alpha+\theta$ y $\alpha+\kappa$, respectivamente. En el trabajo de Maeda y col. (146) destaca la generación de una alúmina de $61 \mathrm{~m}^{2} / \mathrm{g}$ por calcinación a $1150{ }^{\circ} \mathrm{C}$ de una pseudo-bohemita, generada por precipitación de sulfato de aluminio y aluminato sódico en presencia de ácido glucorónico, sin embargo la proporción de fase alfa estimada es próxima al $30 \%$. Zhu y col. (147) fabricaron gamma-alúminas de muy alta superficie calcinando el hidróxido de aluminio formado por precipitación de una solución de aluminato sódico en ácido acético en presencia de un tensoactivo no iónico. La superficie decrece rápidamente al elevar la temperatura, pero aún es de $68 \mathrm{~m}^{2} / \mathrm{g}$ tras una calcinación a $1200{ }^{\circ} \mathrm{C}$, sin embargo no se especifica las fases cristalográficas presentes.

En los dos últimos casos, la morfología fibrilar parece ser el motivo del retraso en la sinterización y transformación de fase. Así también, la forma de las partículas parece ser la causa de la menor agregación de las mismas en el trabajo 


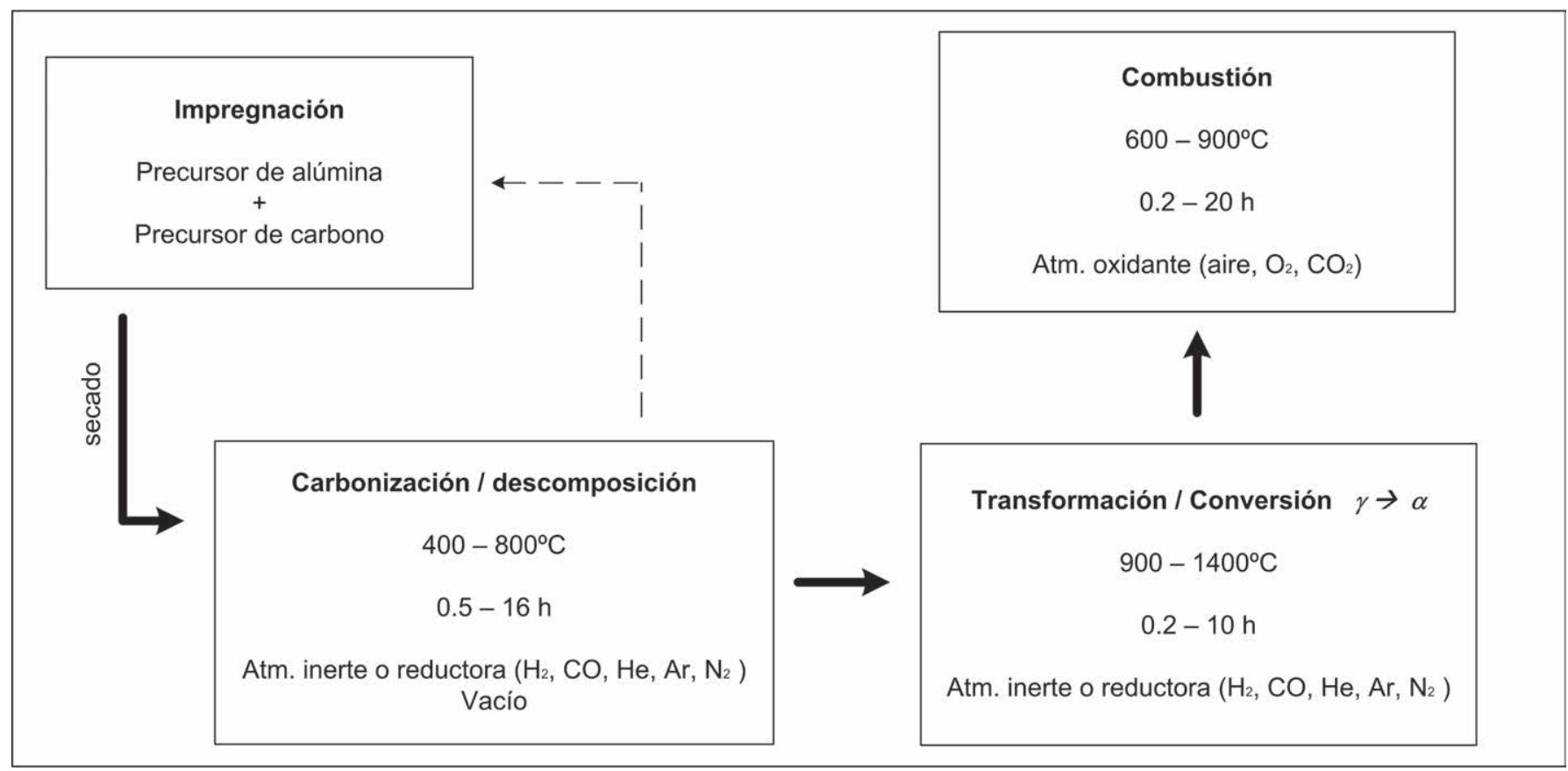

Figura 9 Esquema del procedimiento experimental para la obtención de alfa-alúmina de alta superficie según metodología de las Refs. (183-185).

de Liu y col. (186). La calcinación del precursor AlOOH en forma de partículas esféricas, preparado por emulsión de isopropóxido de aluminio en octanol y acetonitrilo, a $1150{ }^{\circ} \mathrm{C}$ durante 2 horas, produce esferas de alfa-alúmina de $200 \mathrm{~nm}$ de diámetro con superficie variable entre 12 y $21 \mathrm{~m}^{2} / \mathrm{g}$ en función de la velocidad de calentamiento, a 10 y $1{ }^{\circ} \mathrm{C} / \mathrm{min}$ respectivamente.

Empleando sales inorgánicas de aluminio también se ha conseguido sintetizar alúminas con alta superficie específica a través del método de emulsión. Así, Sarikaya y col. (187) mediante la calcinación de soluciones de nitrato de aluminio emulsionadas en aceite mineral obtuvieron una superficie próxima a $80 \mathrm{~m}^{2} / \mathrm{g}$ entre $700-1000{ }^{\circ} \mathrm{C}$, que se mantiene a 20 $\mathrm{m}^{2} / \mathrm{g}$ cuando la temperatura supera $1200^{\circ} \mathrm{C}$. Estos autores sugieren que la baja temperatura de formación de alfa-alúmina es debida la generación de un precursor intermedio de tipo diásporo.

Así mismo, también ha sido posible la generación de alfaalúmina porosa estable a alta temperatura mediante otro tipo de rutas sintéticas. Por ejemplo, Zeng y col. (188) sintetizaron nanopartículas de $\alpha-\mathrm{Al}_{2} \mathrm{O}_{3}$ de $25 \mathrm{~nm}$ de diámetro medio y con una superficie de $51 \mathrm{~m}^{2} / \mathrm{g}$, por liofilización de un gel de bohemita, preparado a partir de una solución acuosa de tricloruro de aluminio, amoniaco y ácido acético, y posterior calcinación a $1100^{\circ} \mathrm{C}$ durante 2 horas. Por otro lado, Chuach y col. (148) obtuvieron $\alpha-\mathrm{Al}_{2} \mathrm{O}_{3}$ de 61 y $68 \mathrm{~m}^{2} / \mathrm{g}$ por calcinación durante 12 horas a $1200{ }^{\circ} \mathrm{C}$ de pseudo-bohemita bien cristalizada, obtenida mediante reacción de una disolución de nitrato de aluminio con hidróxido amónico y elevado tiempo de digestión a $100{ }^{\circ} \mathrm{C}, 8$ y 16 días respectivamente.

El uso de precursores de naturaleza no alcoxídica atrae cada vez más una mayor atención en la síntesis de $\alpha-\mathrm{Al}_{2} \mathrm{O}_{3}$ de elevada porosidad y superficie, así como también el empleo de técnicas de mayor viabilidad económica y la reutilización de residuos de aluminio, por el beneficio medioambiental que implica la adopción de estas medidas (189). Rajendran y col. (96) mediante gelificación de una solución de formoacetato de aluminio, generada por reacción entre aluminio en polvo y los correspondientes ácidos carboxílicos, sintetizaron $\alpha-\mathrm{Al}_{2} \mathrm{O}_{3}$ de $11 \mathrm{~m}^{2} / \mathrm{g}$ a $975^{\circ} \mathrm{C}$, superficie que disminuye por debajo de $1 \mathrm{~m}^{2} / \mathrm{g}$ al elevar a $1200{ }^{\circ} \mathrm{C}$. Martín-Ruíz y col. (121) sintetizaron $\alpha-\mathrm{Al}_{2} \mathrm{O}_{3}$ de 9 y $12 \mathrm{~m}^{2} / \mathrm{g}$ a través del empleo de una máscara de polímero lineal y soluciones de tricloruro de aluminio, preparadas con el metal procedente de distintos envases residuales. Tras la disolución de los mismos en ácido clorhídrico, se llevó a cabo la precipitación de un gel de bohemita mediante la adición de hexametilentetramina en presencia del epoxi epiclorohidrina-bisfenol $A$. Tras una combustión a $1200{ }^{\circ} \mathrm{C}$ durante 30 minutos se obtuvo agregados nanocristalinos de alfa-alúmina $(100 \mathrm{~nm})$ con una superficie de $9 \mathrm{~m}^{2} / \mathrm{g}$, que aumenta a $12 \mathrm{~m}^{2} / \mathrm{g}$ cuando el tratamiento térmico consiste en una etapa de carbonización a $1200{ }^{\circ} \mathrm{C}$ durante 3 horas seguida de una combustión a $800{ }^{\circ} \mathrm{C}$.

Es conocido el método de impregnación de carbón activado con precursores inorgánicos para generar óxidos de muy alta superficie específica y / o un tamaño de partícula muy pequeño (155). Sin embargo, con el óxido de aluminio además se ha de tener en cuenta la drástica reducción de superficie consecuencia de la transformación de fase hacia alfa. Con objeto de prevenir la sinterización y el colapso de los poros durante la transición de fases, y obtener así una alfa-alúmina de elevada superficie estable a alta temperatura, se pueden emplear distintos agentes generadores de carbón: polímeros orgánicos de origen natural o sintético, como polímeros de ácidos policarboxílicos (184), carbones vegetales o derivados del petróleo y carbohidratos, como almidones y azúcares, especialmente sacarosa $(183,185)$. En general la estrategia seguida consiste en cuatro etapas esquematizadas en la Figura 9: 1) impregnación, 2) carbonización a baja temperatura, 3) transformación/conversión de fase en atmósfera inerte a alta temperatura y 4) combustión del carbón en atmósfera oxidante. En concreto, Toombs y col. (183), por impregnación de un aerogel de alúmina con sacarosa, seguido de las correspondientes etapas de carbonización, conversión y oxidación a $500{ }^{\circ} \mathrm{C}$ y $700{ }^{\circ} \mathrm{C}$, cuyos principales parámetros 
TABLA II. RESUMEN DE LOS PARÁMETROS DE SÍNTESIS Y SUPERFICIES ESPECÍFICAS DE ALFA-ALÚMINAS OBTENIDAS SEGÚN LAS PATENTES DE TOMMBS Y COL. (183), HOLLER (184), MURRELl y COL. (185).

\begin{tabular}{|c|c|c|c|c|c|c|c|c|c|c|c|}
\hline \multirow{2}{*}{ Precursores } & \multicolumn{3}{|c|}{ Carbonización } & \multicolumn{3}{|c|}{ Transformación } & \multicolumn{3}{|c|}{ Combustión } & \multirow{2}{*}{$\frac{\alpha-\mathrm{Al}_{2} \mathrm{O}_{3}}{\mathrm{~S}_{\mathrm{BET}}\left(\mathrm{m}^{2} / \mathrm{g}\right)}$} & \multirow{2}{*}{ Ref. } \\
\hline & $\mathrm{T}\left({ }^{\circ} \mathrm{C}\right)$ & t (h) & atm & $\mathrm{T}\left({ }^{\circ} \mathrm{C}\right)$ & $t(h)$ & atm & $\mathrm{T}\left({ }^{\circ} \mathrm{C}\right)$ & t (h) & atm & & \\
\hline \multirow[b]{2}{*}{ Arogel + sacarosa } & 400 & 0.5 & $\mathrm{He}$ & 1300 & 0.25 & $\mathrm{Ar}$ & 500 & 5.5 & aire & 86 & \multirow[b]{2}{*}{ (183) } \\
\hline & 400 & 1 & $\mathrm{He}$ & 1320 & 2 & $\mathrm{Ar}$ & $\begin{aligned} & (500 \\
+ & (700\end{aligned}$ & $\begin{array}{l}\text { 1) }+ \\
\text { 1) }\end{array}$ & aire & 45 & \\
\hline $\begin{array}{c}\mathrm{Al}(\mathrm{O}-\mathrm{iPr})_{2}+\mathrm{Gel} \\
\text { polimérico }\end{array}$ & 510 & 2 & vacío & 1250 & 1 & $\mathrm{Ar}$ & 550 & 13 & aire & 88 & (184) \\
\hline \multirow{4}{*}{$\begin{array}{c}\text { Extruido } \gamma-\mathrm{Al}_{2} \mathrm{O}_{3}+ \\
\text { sacarosa }\end{array}$} & 600 & 16 & $\mathrm{He}$ & $1150 / 1200$ & 16 & $\mathrm{Ar}-\mathrm{H}_{2}(15 \%)$ & 680 & 16 & $\mathrm{He}-\mathrm{O}_{2}(20 \%)$ & $38 / 21$ & \multirow{5}{*}{ (185) } \\
\hline & 600 & 16 & $\mathrm{He}$ & 1150 & 16 & $\mathrm{Ar}-\mathrm{H}_{2}(15 \%)$ & 892 & 16 & $\mathrm{He}-\mathrm{O}_{2}(20 \%)$ & $26-43$ & \\
\hline & 600 & 16 & $\mathrm{He}$ & 1300 & 16 & $\mathrm{Ar}-\mathrm{H}_{2}(15 \%)$ & 700 & 16 & $\mathrm{He}-\mathrm{O}_{2}(20 \%)$ & 25 & \\
\hline & 600 & 16 & $\mathrm{He}$ & 1200 & 16 & $\mathrm{Ar}-\mathrm{H}_{2}(15 \%)$ & $1000 / 1100$ & 2 & Aire $+\mathrm{H}_{2} \mathrm{O} v$ & $43 / 12$ & \\
\hline $\begin{array}{l}\text { Solución } \mathrm{Al}\left(\mathrm{NO}_{3}\right)_{3} \\
+ \text { carbono }\end{array}$ & 300 & 2 & $\mathrm{He}$ & 1200 & 18 & $\mathrm{Ar}-\mathrm{H}_{2}(15 \%)$ & 872 & 18 & Aire $+\mathrm{H}_{2} \mathrm{O}_{v}$ & $\begin{array}{c}\gamma+\alpha-\mathrm{Al}_{2} \mathrm{O}_{3} \\
138\end{array}$ & \\
\hline
\end{tabular}

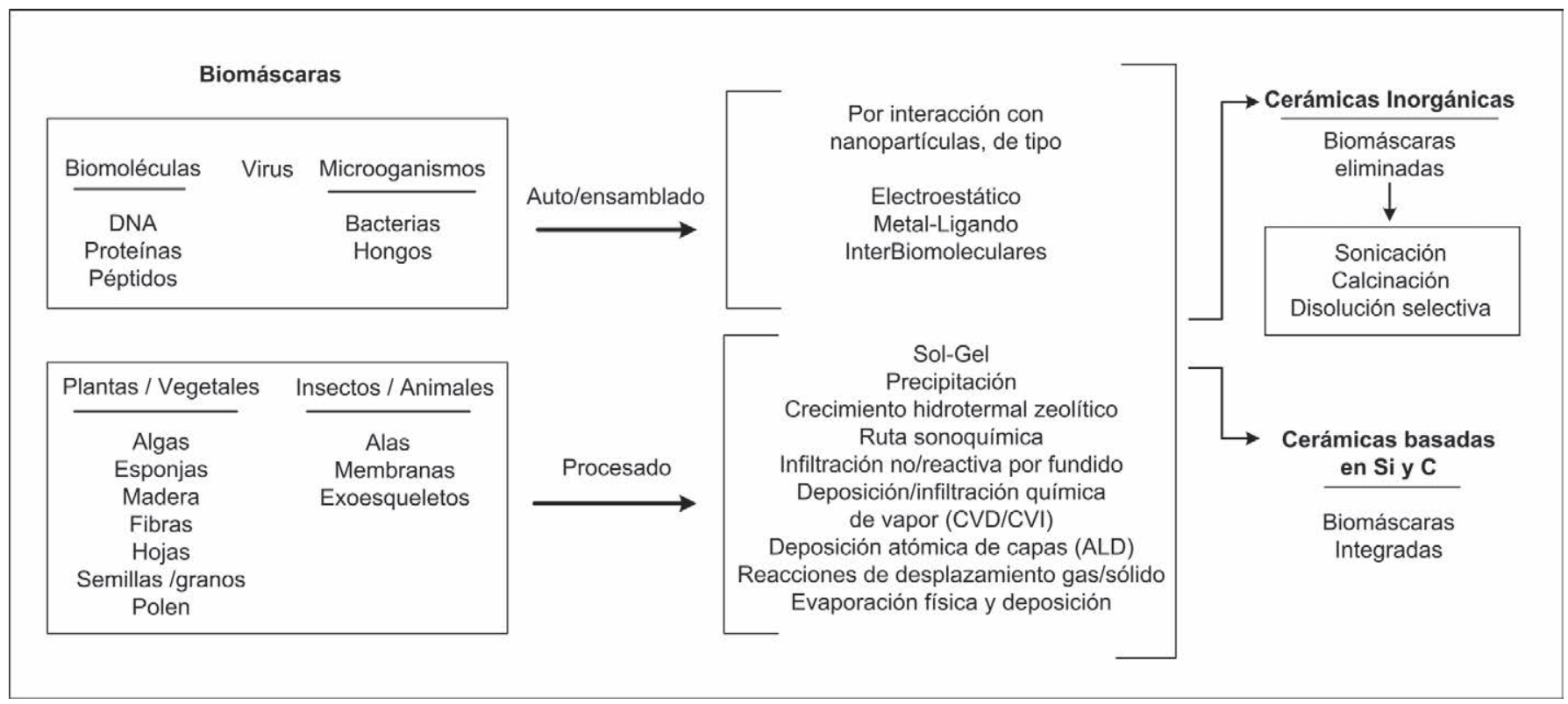

Figura 10. Esquema de las diferentes metodologías de síntesis biomimética en base al trabajo de Fan y col. (193).

se resumen en la Tabla II, llegan a obtener alfa-alúmina de 86 y $45 \mathrm{~m}^{2} / \mathrm{g}$ respectivamente. Señalan que la alúmina obtenida por su método sólo es estable a temperaturas inferiores a $800{ }^{\circ} \mathrm{C}$, y que etapas de oxidación a temperaturas superiores a $1000{ }^{\circ} \mathrm{C}$ no son efectivas por provocar pérdida de superficie específica.

Por su parte, Holler (184) describe la síntesis de una alúmina alfa de $88 \mathrm{~m}^{2} / \mathrm{g}$ y con tamaño de cristalita superior a $100 \AA ̊$, preparada a partir de un gel de isopropóxido de aluminio-poliacrilato bajo las condiciones resumidas en la Tabla II. Al igual que los autores anteriores, Holler apunta que la alúmina que se llega a obtener a través de esta metodología, de al menos $40 \mathrm{~m}^{2} / \mathrm{g}$, es estable en procesos que no superen los $800{ }^{\circ} \mathrm{C}$.

La modificación sustancial introducida por Murrell y col. (185) consiste en el empleo de un precursor de alúmina concreto, un extruido de fase gamma de alta pureza con poros estrechos entre $20-100 \AA$ A. Tras la impregnación con sacarosa y el tratamiento térmico descrito en la Tabla II, llegan a obtener extruidos de fase alfa con una superficie específica comprendida entre 25 - $66 \mathrm{~m}^{2} / \mathrm{g}$ según condiciones de operación. Estos autores indican que la alúmina generada a través de esta patente llega a soportar al menos $1000{ }^{\circ} \mathrm{C}$ en presencia de humedad sin pérdida sustancial de superficie. Como ejemplo, señalan que la superficie específica alcanzada tras la oxidación en aire húmedo a $1000{ }^{\circ} \mathrm{C}$ durante 2 horas es de $43 \mathrm{~m}^{2} / \mathrm{g}$, y que disminuye a $12 \mathrm{~m}^{2} / \mathrm{g}$ cuando la temperatura aumenta a $1100{ }^{\circ} \mathrm{C}$. Por otro lado comprobaron que se obtienen resultados significativamente superiores si se parte de carbón impregnado con una solución de nitrato de aluminio, sin embargo con este nuevo procedimiento no llegaron a obtener una conversión completa de la gamma-alúmina.

\section{SÍNTESIS BIOMIMÉTICA. MÉTODO DE BIO-RÉPLICA DE LIGNOCELULÓSICOS}

La tecnología de bio-réplica ha revolucionado la fabricación de cerámicas con propiedades y características, tanto técnicas, funcionales como estéticas, mejoradas e innovadoras (190, 


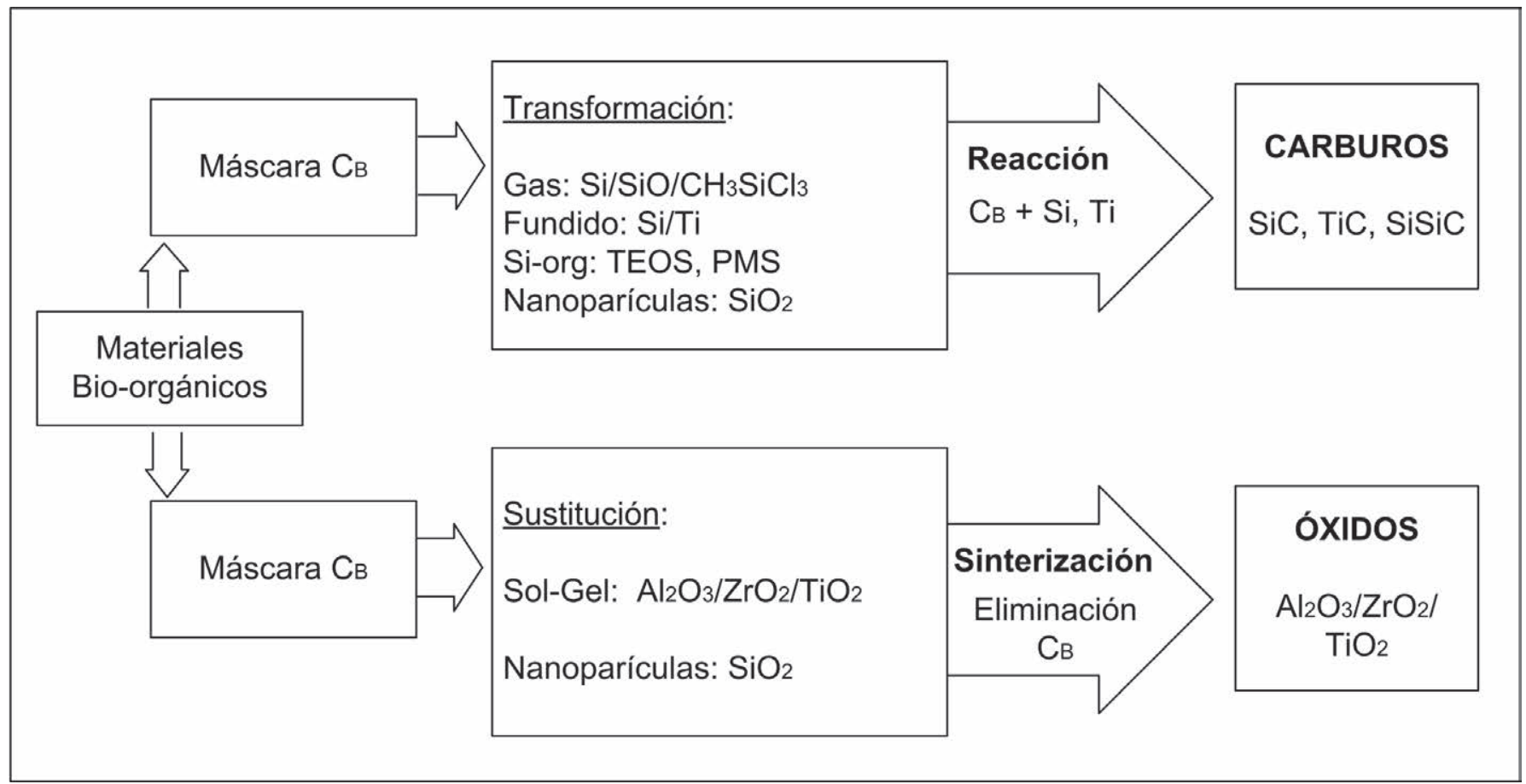

Figura 11 Esquema de procesado para la síntesis de carburos metálicos y óxidos cerámicos a partir de máscaras lignocelulósicas. Adaptación de Ref. (199).

191). Esta técnica de síntesis mimética utiliza preformas de origen natural o biomáscaras para generar cerámicas morfológicamente estructuradas, que encuentra aplicación en muy diferentes áreas: electrónica, magnética, fotónica, biotecnología, ingeniería tisular, transducción, filtración y catálisis (192-194), así como en la síntesis de composites derivados del carbón (195).

Una extensa y completa revisión bibliográfica sobre la mineralización de elementos naturales es la realizada por Fan y col. (193). Los diferentes materiales utilizados como biomáscaras y rutas de procesado se esquematizan en la Figura 10.

Entre el amplio abanico de materiales susceptibles de utilizarse como máscaras destacan los lignocelulósicos, tanto por ser una materia prima comercial, económica y ecológica, como por poseer un carácter renovable e incluso tener un origen residual, por lo que la síntesis biomimética de estos elementos es considerada un proceso de revalorización y de generación de eco-cerámicas (196-198).

La metodología empleada es muy diversa, en función de las características y propiedades del material cerámico que se desee obtener, pudiéndose emplear para ello gran variedad de precursores, desde sales hasta alcóxidos metálicos, como de preformas naturales (fundamentalmente madera, pero también fibras y semillas). El método se basa en una etapa de impregnación-infiltración del material lignocelulósico (bien al natural o prepirolizado) con una solución precursora, seguida de un tratamiento térmico cuyo objeto es, por un lado, la transformación del precursor y consolidación (nucleación/ crecimiento/sinterización) del material cerámico y, por otra, la eliminación parcial o total del cuerpo carbonoso. Así, el soporte puede llegar a formar parte del producto cerámico final, mediante un proceso de pirólisis-carbonización como en la síntesis de carburos metálicos, o bien puede ser eliminado en un proceso de combustión con objeto de generar óxidos cerámicos. Estas dos aproximaciones corresponden a las técnicas Reactiva y Moldeo, esquematizadas en la Figura 11, descritas por Sieber y Singh para maderas (199). La Figura 12 resume las principales rutas de procesado para la transformación-réplica de materiales lignocelulósicos en materiales cerámicos según el esquema propuesto por Greil y col. $(38,192)$.

La mayoría de trabajos han tenido por objeto la fabricación de carburos, como el SiC y derivados del mismo, mediante infiltración de compuestos en forma fundida o vapor y posterior reacción con el material carbonoso previamente pirolizado (200-202). Sin embargo, el interés por las bio-réplicas cerámicas basadas en óxidos cerámicos ha ido en aumento. Algunos ejemplos son las cerámicas celulares basadas en $\mathrm{Al}_{2} \mathrm{O}_{3}, \mathrm{TiO}_{2}$ y $\mathrm{ZrO}_{2}$ entre otras $(203,204)$.

\section{Revisión del estado del arte en la síntesis de alúmina por bio-réplica}

El procedimiento de bio-réplica se ha utilizado en la síntesis de alúmina empleando diferentes tecnologías y diversos materiales lignocelulósicos como biomáscaras. Así, Patel y Padhi (205) generaron fibras porosas de alúmina utilizando como máscaras fibras de yute alcalizadas con $\mathrm{NaOH} 0.2 \mathrm{M}$ a reflujo a $110{ }^{\circ} \mathrm{C}$, las cuales infiltraron durante 30 minutos con una solución precursora de tricloruro de aluminio, preparada por oxidación de aluminio metal. Tras una etapa de calcinación obtuvieron alúminas con valores de superficie B.E.T. $\left(S_{\text {BET }}\right)$ de $102,56,3$ y $1 \mathrm{~m}^{2} / \mathrm{g}$ a $800,1000,1200$ y $1600{ }^{\circ} \mathrm{C}$ respectivamente. La superficie disminuye considerablemente cuando la transformación a alfa-alúmina tiene lugar. Estos autores concluyeron que el mecanismo por el cual se generan las fibras cerámicas consiste en el intercambio de los iones $\mathrm{Na}^{+}$ (del álcali-celulosa formada tras el tratamiento alcalino) por los cationes $\mathrm{Al}^{3+}$ de la solución precursora. Además, indican que 
Material Lignocelulósico

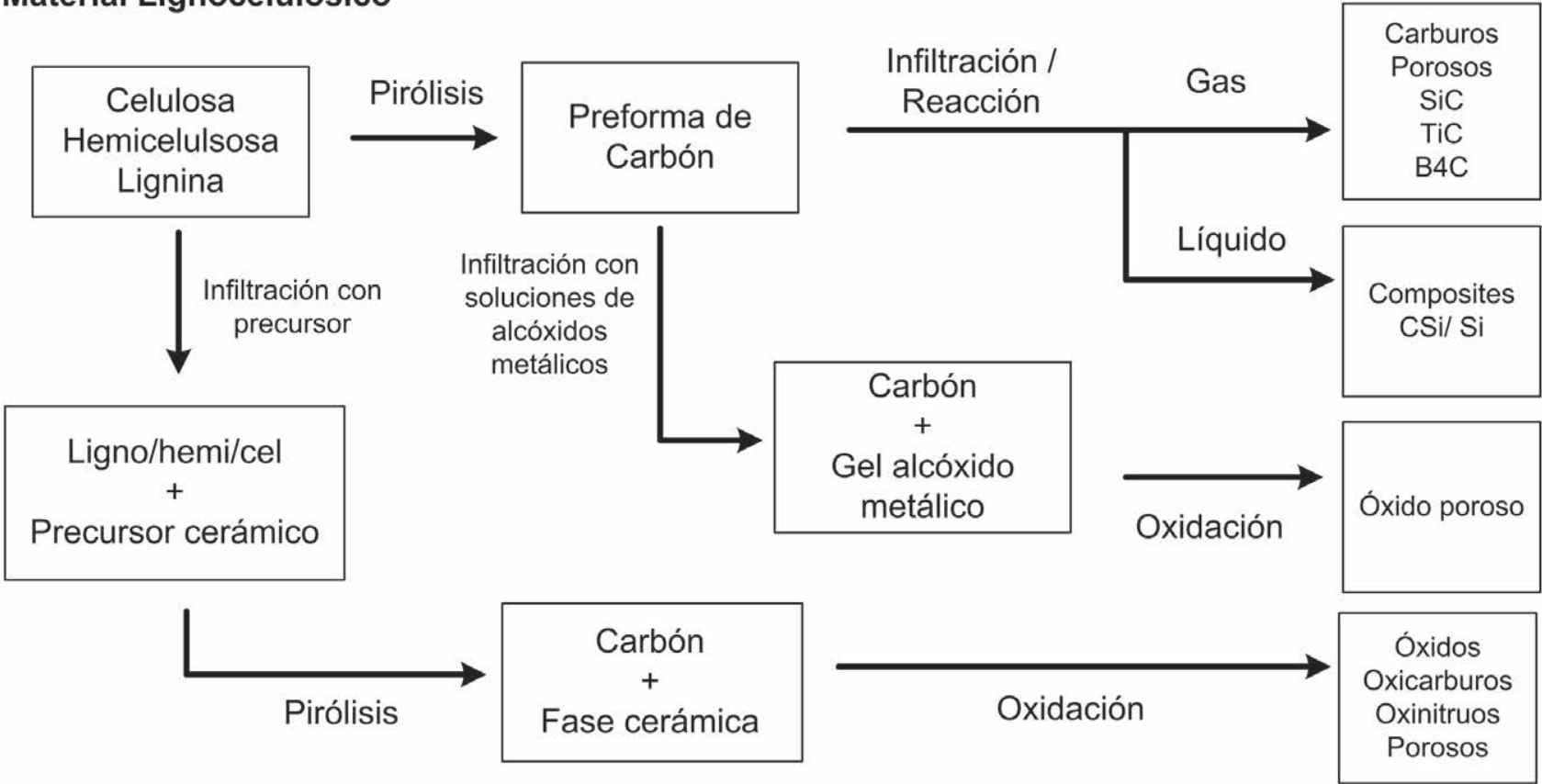

Figura 12 Rutas de procesado para la síntesis de estructuras cerámicas mediante biomimética de materiales lignocelulósicos. Adaptación de Ref. (160) en base a Ref. $(38,192)$.

la mimetización de las fibras lignocelulósicas está favorecida por la presencia de materia mineral como $\mathrm{Fe}_{2} \mathrm{O}_{3}, \mathrm{Na}_{2} \mathrm{O}, \mathrm{K}_{2} \mathrm{O}$, $\mathrm{CaO}, \mathrm{MgO}$ y $\mathrm{P}_{2} \mathrm{O}_{5}$, que actuarían como catalizadores y agentes fundentes.

Sin embargo, el compuesto álcali-celulosa no sólo no parece justificar el mecanismo de síntesis biomimética propuesto por Patel y Padhi (a la luz de otros muchos trabajos en los que se replican tanto materiales celulósicos como no celulósicos sin alcalizar), sino que también origina una cierta proporción de $\beta$-alúmina que impurifica la alúmina obtenida; un efecto similar tendría el $\mathrm{K}_{2} \mathrm{O}$ y el $\mathrm{CaO}$, generando aluminatos cálcicos y potásicos. Además, la presencia de $\mathrm{Fe}_{2} \mathrm{O}_{3}$ favorecería la sinterización de $\alpha-\mathrm{Al}_{2} \mathrm{O}_{3}$, contribuyendo a la disminución de superficie específica observada por estos autores.

Fan y col. (206), con un procedimiento similar al anteriormente expuesto, obtuvieron fibras mesoporosas de gamma-alúmina con una $S_{\mathrm{BET}}$ de 127.6 y $125.1 \mathrm{~m}^{2} / \mathrm{g}$ tras una etapa de calcinación en aire a 800 y $1000{ }^{\circ} \mathrm{C}$, respectivamente, durante 2 horas; superficie que decrece hasta $10.2 \mathrm{~m}^{2} / \mathrm{g}$ a $1200{ }^{\circ} \mathrm{C}$ debido a la transformación a $\alpha-\mathrm{Al}_{2} \mathrm{O}_{3}$. El método seguido consiste en la infiltración de fibras de algodón con una solución acuosa de tricloruro de aluminio al $5 \%$ durante 2 minutos, secada posteriormente a $80^{\circ} \mathrm{C}$ durante 24 horas previamente a la etapa de calcinación. En un trabajo posterior (207), partiendo de la misma biomáscara y tras una calcinación a $800{ }^{\circ} \mathrm{C}$ durante 3 horas, se obtuvo una superficie de 110 $\mathrm{m}^{2} / \mathrm{g}$. En este caso se utilizó un sol estable de isopropóxido de aluminio $0.1 \mathrm{M}$, que infiltraron en caliente $\left(90^{\circ} \mathrm{C}\right)$ repetidas veces, eliminando el exceso por succión. Es probable, por tanto, que el uso de un precursor y metodología diferente sean responsables de la disminución de superficie específica.

La bio-réplica de materiales lignocelulósicos también se ha utilizado para obtener alúminas macroporosas de alta temperatura a través de diferentes métodos. El grupo formado por Sieber, Rambo y Cao $(203,204,208)$ obtuvo alfaalúmina a partir de bloques de madera de pino y de ratán, por infiltración asistida a vacío del precursor $\mathrm{Al}\left(\mathrm{OC}_{3} \mathrm{H}_{7}\right)_{3}$ en estado sol. Tras una primera etapa de infiltración y secado a $130^{\circ} \mathrm{C}$, los bloques impregnados son pirolizados a $800{ }^{\circ} \mathrm{C}$ durante 1 hora, tras lo cual se suceden varias etapas adicionales de infiltración sobre el material prepirolizado con objeto de aumentar el rendimiento de alúmina. En una etapa posterior el material carbonoso es calcinado en aire y la alúmina resultante se sinteriza a $1550{ }^{\circ} \mathrm{C}$ durante 3 horas. Los productos finales son piezas porosas uniaxiales de $\alpha-\mathrm{Al}_{2} \mathrm{O}_{3}$ con porosidad del 90-94 \%, densidad geométrica del $0.22-0.38 \mathrm{~g} / \mathrm{cm}^{3}$ y densidad del esqueleto próxima a $3.92 \mathrm{~g} / \mathrm{cm}^{3}$.

Para alcanzarestemismoobjetivo, estos autores propusieron otro método basado en un intermedio de carburo de aluminio. Consiste en la infiltración de aluminio vapor a $1600{ }^{\circ} \mathrm{C}$ a vacío sobre las máscaras lignocelulósicas prepirolizadas a $800{ }^{\circ} \mathrm{C}$, como piezas de ratán, pino $(209,210)$ y fibras sisal $(211)$, con objeto de sintetizar $\mathrm{Al}_{4} \mathrm{C}_{3}$. Posteriormente, éste es oxidado en aire a $1550-1600{ }^{\circ} \mathrm{C}$ durante $2-3$ horas para obtener una estructura de alfa-alúmina densificada, formada por granos de entre $1-4 \mu \mathrm{m}$, pero impurificadas con $\mathrm{CaAl}_{12} \mathrm{O}_{19}$. En el caso del ratán, se llegan a obtener piezas de alúmina con una densidad geométrica y del esqueleto de 0.23 y $3.94 \mathrm{~g} / \mathrm{cm}^{3}$, respectivamente, y con una porosidad del $85 \%$ (209).

Andrade y col. (212) concluyen que a través de este método, las fibras cerámicas de alúmina reproducen mejor la microestructura de las de sisal que al emplear métodos de infiltración convencionales, en los que se usan precursores de $\mathrm{AlCl}_{3}$ y $\mathrm{Al}\left(\mathrm{OC}_{3} \mathrm{H}_{7}\right)_{3}$.

Por último, cabe mencionar también el empleo de máscaras sintéticas de origen celulósico, estructuradas (213) y de forma más reciente no estructuradas (214). Así, usando papel de filtro Whatman 50 como soporte celulósico, Shigapov y 
col. (213) documentan la generación de alúmina con una $\mathrm{S}_{\mathrm{BET}}$ de $322 \mathrm{~m}^{2} / \mathrm{g}$ tras una calcinación durante 2 horas a $800{ }^{\circ} \mathrm{C}$, superficie que diminuye hasta $21 \mathrm{~m}^{2} / \mathrm{g}$ cuando la calcinación se realiza a $1050{ }^{\circ} \mathrm{C}$ durante 12 horas. Por su parte, Zhong y col. (214) proponen fabricar alúminas mesoporosas empleando máscaras celulósicas reciclables, que se recuperan parcialmente antes de la etapa de calcinación. Para ello utilizan el derivado metilcelulosa, que se mantiene sólido por encima de $50{ }^{\circ} \mathrm{C}$, al que infiltran en caliente una suspensión de $\mathrm{Al}(\mathrm{OH})_{3}$, generada por reacción entre $\mathrm{AlCl}_{3}$ y $\mathrm{NaAlO}_{2}$. Tras 12 horas de contacto a temperaturas entre $50-90^{\circ} \mathrm{C}$, se recupera la máscara por filtrado. La torta de hidróxido de aluminio, una vez lavada y secada a $80{ }^{\circ} \mathrm{C}$ durante 24 horas, se calcina a $600{ }^{\circ} \mathrm{C}$ durante $2-3$ horas, generado gamma-alúmina de hasta $316 \mathrm{~m}^{2} / \mathrm{g}$. El porcentaje de recuperación de metilcelulosa llega hasta un $63 \%$.

Las alúminas así generadas presentan una estructura jerárquica de poros de interés en distintas aplicaciones energéticas sostenibles, como es en la fabricación de sensores de gases (215).

\section{RESUMEN FINAL}

En este trabajo se han descrito diferentes procedimientos sintéticos para la obtención de alúmina porosa y de alta superficie específica, subrayando la dificultad de obtención de las mismas y su inestabilidad a temperaturas elevadas, debido a la reducción drástica de superficie que el óxido de aluminio experimenta durante su transformación hacia $\alpha$-alúmina. Una de las principales estrategias consiste en retrasar el cambio hacia fase alfa, estabilizando las fases metaestables utilizando aditivos. La obtención de alfa-alúmina de elevada superficie específica, pasa por evitar, o al menos reducir en lo posible, la sinterización y crecimiento de los cristales $\alpha-\mathrm{Al}_{2} \mathrm{O}_{3}$

El método de bio-réplica de lignocelulósicos destaca por ser un método económico y ecológico que permite la generación de cerámicas con una estructura de poros jerárquica. A través del mismo se han sintetizado alúminas con características muy diversas, desde fibras cerámicas dotadas con superficies específicas superiores a $100 \mathrm{~m}^{2} / \mathrm{g}$ a temperaturas de $1000{ }^{\circ} \mathrm{C}$, hasta piezas porosas uniaxiales de alfa-alúmina sinterizada.

\section{AGRADECIMIENTOS}

M.Benítez-Guerrero desea agradecer al ConsejoSuperior de Investigaciones Científicas la concesión de la beca JAEpredoc con la que ha realizado la tesis doctoral titulada "Síntesis y Caracterización de Alúminas Bioinspiradas de Alta Superficie Específica".

Así mismo, se agradece la financiación económica del MICINN proyecto MAT2010-17753.

\section{BIBLIOGRAFÍA}

1. I. Nettleship, "Application of porous ceramics". Key Eng. Mat., 122-124 (1996) 305-324.

2. P. Greil, "Advance Engineering Ceramics". Adv. Eng. Mater., 4 (2002) 247253.

3. Z.Y. Yuan, B.L. Su, "Insights into hierarchically meso-macroporous structured materials". J. Mater. Chem., 16 (2006) 663-677.
4. M.L.K. Hoa, M. Lu, Y. Zhang, "Preparation of porous materials with ordered hole structure". Adv. Colloid Interfac., 121 (2006) 9-23.

5. R.A. Hay, "Fine alpha alumina ultrafiltration membranes". Patente $\mathrm{n}^{\circ}$ 4968426. (EE.UU., 11/1990).

6. M.A. Anderson, G. Sheng, "Microporous alumina ceramic membrane". Patente $n^{\circ}$ : 5208190. (EE.UU., 5/1993)

7. M.S. Yahnke, G. Shlomo, M.A. Anderson, "Battery utilizing ceramic membranes". Patente $n^{\circ}$ : 5208121. (EE.UU., 5/1993).

8. C.N. McGarry, T.M. Wehrenberg, "Apparatus and method of filtering molten metal using honeycomb structure of sintered alumina as filter element". Patente ${ }^{\circ}$ : 4591383. (EE.UU., 3/1986).

9. J.F. Zievers, "Hot gas filter". Patente no: 4968467. (EE.UU., 11/1990).

10. J. Sánchez, T.T. Tsotsis, Current developments and future research in catalytic membrane reactors. En: A. J. Burggraaf and L. Cot, eds. Fundamentals of Inorganic Membrane Science and Technology, (Elsevier Science, 1996), pp. 529-568.

11. Y. Ishii, N. Akita, "Cleaning method for exhaust gas containing ammonia and silane". Patente $\mathrm{n}^{\mathrm{O}}$ : 5632964. (EE.UU., 5/1997).

12. Y. Araki, T. Mizuno, "Filter for purifying exhaust gases". Patente $\mathrm{n}^{\circ}$ : EP 0 766993 B1. (Europa, 3/2003).

13. M. Uenishi, I. Tan, H. Tanaka, "Catalytic converter for cleaning exhaust gas". Patente n': 6808687 B1. (EE.UU., 10/2004).

14. K. Volchek, S. Mortazavi, H. Whittaker, "Removal of arsenic from aqueous liquids with selected alumina". Patente $n^{\circ}: 5556545$. (EE.UU., 9/1996).

15. B.K. Horden, "Chemistry of alumina, reactions in aqueous solutions and its applications in water treatment". Adv. Colloid Interfac., 110 (2004) 19-48.

16. W. Cai, J. Yu, M. Jaroniec, "Template-free synthesis of hierarchical spindlelike $\gamma-\mathrm{Al}_{2} \mathrm{O}_{3}$ materials and their adsorption affinity towards organic and inorganic pollutants in water". J. Mater. Chem., 20 (2010) 4587-4594.

17. G. Busca, The surface acidity and basicity of solid oxides and zeolites. (17a) En: J. L. G. Fierro, ed. Metal Oxides. Chemistry and Applications., (Taylor \& Francis, New York, 2006), pp. 247-318.

18. M. Pineda, J.M. Palacios, "The effect of surface and thermal treatment on $\gamma-\mathrm{Al}_{2} \mathrm{O}_{3}$ as a catalyst of the Claus reaction at low temperature". Appl. Catal. A-Gen., 158 (1997) 307-321.

19. E. Laperdrix, A. Sahibed-Dine, G. Costentin, O. Saur, M. Bensitel, C. Nédez, A.B. Mohamed-Saad, J.C. Lavalley, "Reduction of sulfate species by $\mathrm{H}_{2} \mathrm{~S}$ on different metal oxides and promoted aluminas". Appl. Catal. B-Environ., 26 (2000) 71-80.

20. B.C. Gates, "Supported metal clusters: Synthesis, structure and catalysis ". Chem. Rev., 95 (1995) 511-522.

21. M. Trueba, S.P. Trasatti, " $\gamma$-alumina as a support for catalysts: A review of fundamentals aspects". Eur. J. Inorg. Chem., 17 (2005) 3393-3403.

22. H. Topsoe, B.S. Clausen, F.E. Massoth. Hydrotreating Catalysis. (SpringerVerlag, Berlin, 1996).

23. J.M. Berty, Ethylene oxide synthesis. En: B. E. Leach, ed. Applied Industrial Catalysis, (Academic Press, Orlando, 1983), pp. 207-238.

24. P. Gélin, M. Primet, "Complete oxidation of methane at low temperature over noble metal based catalysts: A review". Appl. Catal. B-Environ., 39 (2002) 1-37.

25. A.H.D. Aza, J. Chevalier, G. Fantozzi, M. Schehl, R. Torrecillas, “Crack growth resistance of alumina, zirconia and zirconia toughened alumina ceramics for joint prostheses". Biomaterials, 23(3) (2002) 937-945.

26. A.H.D. Aza, J. Chevalier, G. Fantozzi, M. Schehl, R. Torrecillas, "Slowcrack-growth behavior of zirconia-toughened alumina ceramics processed by different methods". J. Am. Ceram. Soc., 86(1) (2003) 115-120.

27. P.N.D. Aza, A.H.D. Aza, S.D. Aza, "Crystalline bioceramic materials". Bol. Soc. Esp. Ceram. V., 44(3) (2005) 135-145.

28. S. Kobayashi, K. Sugita, K. Matsuo, T. Inoue, "Reconstruction of the sellar floor during transsphenoidal operations using alumina ceramic". Surg. Neurol., 15 (1981) 196-197.

29. S.F. Hulbert, The use of alumina and zirconia in surgical implants En: L. L. Hench and J. Wilson, eds. An Introduction to Bioceramics, (World Scientific, Singapore, 1993), pp. 25-40.

30. J. Li, G.W. Hastings, Oxide bioceramics: Inert ceramic materials in medicine and dentistry. En: J. Black and G. Hastings, eds. Handbook of Biomaterial Properties, (Chapman \& Hall, London, 1998), pp. 340-353.

31. D.R. Jordan, L.A. Mawn, S. Brownstein, T.M. McEachren, S.M. Gilberg, V. Hill, S.Z. Grahovac, J.P. Adenis, "The bioceramic Orbital implant: A new generation of porous implants". 16 (2000) 347-355.

32. T.N. Kim, Q.L. Feng, Z.S. Luo, F.Z. Cui, J.O. Kim, “Highly adhesive hydroxyapatite coatings on alumina substrates prepared by ion-beam assisted deposition". 99 (1998) 20-23.

33. B. Su, X. He, S. Dhara, J.P. Mansell, "Porous and bioactive alumina ceramics for bone grafts and tissue engineering scaffolds". Key Eng. Mat. 330-332 (2007).

34. B.H. Yoon, W.Y. Choi, H.E. Kim, J.H. Kim, Y.H. Koh, "Aligned porous alumina ceramics with high compressive strengths for bone tissue engineering". Scripta Mater., 58 (2008) 537-540.

35. I. Sopyan, A. Fadli, "Floating porous alumina from protein foamingconsolidation technique for cell culture application". Ceram. Int., 38 (2012) 5287-5291. 
36. S. Joughehdoust, A. Behnamghader, M. Imani, M. Daliri, A.H. Doulabi, E. Jabbari, "A novel foam-like silane modified alumina scaffold coated with nano-hydroxyapatite-poly(e-caprolactone fumarate) composite layer". Ceram. Int., 39 (2013) 209-218.

37. S. Mann, G.A. Ozin, "Synthesis of inorganic materials with complex form". Nature, 382 (1996) 313-318.

38. A. Zamperi, W. Schwieger, C. Zollfrank, P. Greil, Organic preforms of biological origin: Natural tissues as templates for inorganic and zeolitic macrostructures. En: E. Bäuerlein, ed. Handbook of Biomineralization, (Wiley-VCH, Weinheim, 2007), pp. 255-288.

39. L.S. Muñoz, J.B.C. Castelló, Materias primas y aditivos cerámicos. En: F. E. I. S.L, ed. Enciclopedia Cerámica. Castellón, 2002), pp. 172-177.

40. F. Haber, "The hydroxides of aluminum and trivalente iron". Naturwissenschaften, 13 (1925) 1007-1012.

41. F.C. Frary, "Adventures with alumina". Ind. Eng. Chem., 38 (1946) 129131.

42. W.H. Gitzen. Alumina as a Ceramic Material. Special Publicaton N ${ }^{\circ} 4$ Westerville-Ohio, 1970). (a) pp. 3-5; (b) pp. 7-11; (c) pp. 24-26.

43. B.C. Lippens. Structure and texture of aluminas (PhD Thesis, Delft, 1961).

44. A.F. Wells, Binary metal oxides. Structural Inorganic Chemistry (Clarendon Press, Oxford, 1984), pp. 531-572.

45. C.S. John, N.C.M. Alma, G.R. Hays, "Characterization of transitional alumina by solid-state magic angle spinning aluminium NMR". Appl. Catal., 6 (1983) 341-346.

46. M.H. Lee, C.F. Chen, V. Heine, J. Klinowski, "Distribution of tetrahedral and octahedral Al sites in gamma alumina". Chem. Phys. Lett., 265 (1997) 673-676.

47. C. Pecharromán, I. Sobrados, J.E. Iglesias, T. González-Carreño, J. Sanz "Thermal evolution of transitional aluminas followed by NMR and IR spectroscopies ". J. Phys. Chem. B, 103 (1999) 6160-6170.

48. S.J. Wilson, J.D.C. McConnell, "A kinetic study of the system $\gamma-\mathrm{AlOOH} /$ $\mathrm{Al}_{2} \mathrm{O}_{3}$ “. J. Solid State Chem., 34 (1980) 315-322.

49. M.I. Baraton, P. Quintad, "Infrared evidence of order-disorder phase transitions $(\gamma \rightarrow \delta \rightarrow \alpha)$ in $\mathrm{Al}_{2} \mathrm{O}_{3}{ }^{\prime \prime}$. J. Mol. Struct., 79 (1982) 337-340.

50. S. Zhou, R.L. Snyder, "Structures and transformations mechanisms of the $\eta, \gamma$ and $\theta$, transition aluminas". Acta Crystallogr. B, 47 (1991) 617-630.

51. K.Sohlberg, S.J. Pennycook, S.T. Pantelides, "Hydrogen and the structure of the transition aluminas". 121 (1999) 7493-7499.

52. X. Yang, A.C. Pierre, D.R. Uhlmann, "TEM study of boehmite gels and their transformation to $\alpha$-alumina". J. Non-Cryst. Solids, 100 (1988) 371377.

53. C. Morterra, G. Magnacca, "A case study: Surface chemistry and surface structure of catalytic alumina, as studied by vibrational spectroscopy of adsorbed species". Catal. Today, 27 (1996) 497-532.

54. S. Soled, " $\gamma-\mathrm{Al}_{2} \mathrm{O}_{3}$ viewed as a defect oxyhydroxide". J. Catal., 81 (1983) 252 257.

55. G. Busca, V. Lorenzelli, G. Ramis, R.J. Willey, "Surface sites on spinel-type and corundum-type metal oxide powders". Langmuir, 9 (1993) 1492-1499.

56. E. Husson, Y. Repelin, "Structural Studies of transition aluminas. Theta alumina". Eur. J. Sol. State Inor., 33 (1996) 1223-1231.

57. K. Wefers, C. Misra. Oxides and Hydroxides of Alumium (Alcoa Laboratories, Alcoa Technical Paper Nº19, 1987).p. 49

58. B.C. Lippens, J.H.d. Boer, "Study of phase transformations during calcination of aluminum hydroxides by selected area electron diffraction". Acta Crystallogr., 17 (1964) 1312-1321.

59. S.J. Wilson, "The dehydration of boehmite, $\gamma-\mathrm{AlOOH}$ to $\gamma-\mathrm{Al}_{2} \mathrm{O}_{3}$ ". J. Solid State Chem., 30 (1979) 247-255

60. M.F.L. Johnson, J. Mooi, "The origin and types of pores in some alumina catalysts". I. Catal., 10 (1968) 342-354.

61. H.C. Stumpf, A.S. Russel, J.W. Newsome, C.M. Tucker, "Thermal transformations of alumina and alumina hydrates". Ind. Eng. Chem., 42 (1950) 1398-1403.

62. R. Tertian, D. Papée, "Thermal and hydrothermal transformations of alumina". J. Chim. Phys., 55 (1958) 341-353.

63. G. Urretavizcaya, A.L. Cavalieri, J.M.P. López, I. Sobrados, J. Sanz, "Thermal evolution of alumina prepared by the sol-gel technique". J Mater. Synth. Proces., 6 (1998) 1-7.

64. S.C. Arazi, A.R. Rossini, "Estudio por ATD y difracción de rayos X de la transformación de $\gamma$ - en $\alpha-\mathrm{Al}_{2} \mathrm{O}_{3}$ entre 600 y $1500{ }^{\circ} \mathrm{C}^{\prime \prime}$. Bol. Soc. Esp. Ceram. V., 11 (1972) 183-186.

65. S.J. Wilson, M.H. Stacey, "The porosity of aluminum oxide phases derived from well-crystallized boehmite: correlated electron microscope, adsorption, and porosimetry studies". J. Colloid Interf. Sci., 82 (1981) 507517.

66. S.J. Wilson, "Phase transformations and development of microstructure in boehmite/derived transition aluminas". P. Brit. Ceram. Soc., 28 (1979) 281-294.

67. T. Tsuchida, "Preparation of high surface area $\alpha-\mathrm{Al}_{2} \mathrm{O}_{3}$ and its surface properties". Appl. Catal. A-Gen., 105 (1993) 141-156.

68. A. Boumaza, L. Favaro, J. Lédion, G. Sattonnay, J.B. Brubach, P. Berthet, A.M. Huntz, P. Roy, R. Tétot, "Transition alumina phases induced by heat treatment of boehmite: An X-ray diffraction and infrared spectroscopy study". J. Solid State Chem., 182 (2009) 1171-1176.
69. S.J. Gregg, K.S.W. Sing, "The effect of heat treatment on the surface properties of gibbsite. Part III. The Chemicals nature of the products formed". J. Phys. Chem., 56 (1952) 388-391.

70. H. Schaper, E.B.M. Doesburg, P.H.M.d. Korte, L.L.V. Reijen, "Thermal stabilization of high surface area alumina". Solid State Ionics, 16 (1985) 261-266.

71. H. Arai, M. Machida, "Thermal stabilization of catalyst supports and their application to high-temperature catalytic combustion". Appl. Catal. A-Gen., 138 (1996) 161-176.

72. P. Burtin, J.P. Brunelle, M. Pijolat, M. Soustelle, "Influence of surface area and additives on the thermal stablity of transition alumina catalyst supports. II. Kinetic model and interpretation". Appl. Catal., 34 (1987) 239254

73. M.L.F. Johnson, "Surface area stability of aluminas". J. Catal., 123 (1990) 245-259.

74. D.L. Trimm, "Thermal stability catalyst supports". Stud. Surf. Sci. Catal., 68 (1991) 29-51

75. M. Pijolat, M. Dauzat, M. Soustelle, "Influence of water vapour and additives on the surface area stability of $\gamma-\mathrm{Al}_{2} \mathrm{O}_{3}$ ". Solid State Ionics, 50 (1992) 31-39.

76. J.L. Hébrard, P. Nortier, M. Pijolat, M. Soustelle, "Initial Sintering of submicrometer titania anatase powder". J. Am. Ceram. Soc., 73 (1990) 79-84.

77. P.A. Badkar, J.E. Bailey, "The mechanism of simultaneous sintering an phase transformation in alumina". J. Mater. Sci., 11 (1976) 1794-1806.

78. S.V. Raman, R.H. Doremus, M. German, "Characterization and initial sintering of a fine alumina powder". Mater. Sci. Res., 16 (1984) 253-264.

79. R.K. Iler, "Fibrillar colloidal boehmite; Progressive conversion to gamma theta, and alpha aluminas". J. Am. Ceram. Soc., 44 (1961) 618-624.

80. D.S. Tucker, A. Bleier, "Gamma-to-Alpha transformation in spherical aluminum oxide powders". J. Am. Ceram. Soc., 68 (1985) 163-164.

81. J.R. Wynnyckyj, C.G. Morris, "A shear-type allotropie transformation in alumina". Metall. Mater Trans. B, 16 (1985) 345-353.

82. G.C. Bye, G.T. Simpkin, "Influence of $\mathrm{Cr}$ and Fe on formation of $\alpha-\mathrm{Al}_{2} \mathrm{O}_{3}$ from $\gamma-\mathrm{Al}(11) \quad$ Y. Ishii, N. Akita, "Cleaning method for exhaust gas containing ammonia and silane". Patente $n^{\circ}$ : 5632964. (EE.UU., 5/1997).

83. R.B. Bagwell, G.L. Messing, P.R. Howell, "The formation of $\alpha-\mathrm{Al}_{2} \mathrm{O}_{3}$ from $\theta-\mathrm{Al}_{2} \mathrm{O}_{3}$ : the relevance of a "critical size and diffusional nucleation or "synchro-shear"?" J. Mater. Sci., 36 (2001) 1833-1841.

84. C.S. Nordahl, G.L. Messing, "Thermal analysis of phase transformation kinetics in $\alpha-\mathrm{Al}_{2} \mathrm{O}_{3}$ seeded boehmite and $\gamma-\mathrm{Al}_{2} \mathrm{O}_{3}{ }^{\prime \prime}$. Thermochim. Acta, 318 (1998) 187-199.

85. R.G. Bagwell, G.L. Messing "Effect of seeding and water vapour on the nucleation and growth of $\alpha-\mathrm{Al}_{2} \mathrm{O}_{3}$ from $\gamma-\mathrm{Al}_{2} \mathrm{O}_{3}$ ". J. Am. Ceram. Soc., 82 (1999) 825-832

86. B.C. Lippens, J.J. Steggerda, Active alumina. En: B. G. Linsen, ed. Physical and Chemical Aspects of Adsorbents and Catalysts, (Academic Press, London, 1970), pp. 171-211.

87. H.D. Ruan, R.L. Frost, J.T. Kloprogge, L. Duong, “Far-infrared spectroscopy of alumina phases". Spectrochim. Acta A, 58 (2002) 265-272.

88. T. Tsuchida, "Preparation and reactivity of acicular $\alpha-\mathrm{Al}_{2} \mathrm{O}_{3}$ from synthetic diaspore $\mathrm{\beta}_{-} \mathrm{Al}_{2} \mathrm{O}_{3} \bullet \mathrm{H}_{2} \mathrm{O}$ “. Solid State Ionics, 63-65 (1993) 464-470.

89. A. Kaiser, D. Spron, H. Bertagnolli, "Phase transformations and control of habit in lyothermal aynthesis of $\alpha-\mathrm{Al}_{2} \mathrm{O}_{3}$. J. Eur. Ceram. Soc., 14 (1994) 77-83.

90. W.L. Suchanek, "Hydrothermal synthesis of alpha alumina $\left(\alpha-\mathrm{Al}_{2} \mathrm{O}_{3}\right)$ powders: Study of the processing variables and growth mechanisms". I Am. Ceram. Soc., 93 (2010) 399-412.

91. T. Tsuchida, K. Horigome, "The effect of grinding on the thermal decomposition of alumina monohydates, $\alpha$ - and $\beta-\mathrm{Al}_{2} \mathrm{O}_{3} \bullet \mathrm{H}_{2} \mathrm{O}^{\prime \prime}$. Thermochim. Acta, 254 (1995) 359-370.

92. B.B. Bokhonov, I.G. Konstanchuk, V.V. Boldyrev, "Structural and morphological changes during the mechanical activation of nano-size particles". Mater. Res. Bull., 30 (1995) 1277-1284.

93. K.J.D. MacKenzie, J. Temuujin, M.E. Smith, P. Angerer, Y. Kameshima, "Effect of mechanochemical activation on the thermal reactions of boehmite $(\gamma-\mathrm{AlOOH})$ and $\gamma-\mathrm{Al}_{2} \mathrm{O}_{3}{ }^{\prime \prime}$. Thermochim. Acta, 359 (2000) 87-94.

94. H. Yanagida, G. Yamaguchi, J. Kubota, "The role of water vapour in formation of alpha alumina from transient alumina". J. Ceram. Assoc. Japan, 74 (1966) 11-17.

95. M. Pijolat, M. Dauzat, M. Soustelle, "Influence of additives an water vapour on the transformation of transition aluminas into alpha alumina". Thermochim. Acta, 122 (1987) 71-77.

96. M. Rajendran, A.K. Bhattacharya, "Low-temperature formation of alpha alumina powders from carboxylate and mixed carboxylate precursors". Mater. Lett., 39 (1999) 188-195.

97. R.N. Das, A. Bandyopadhyay, S. Bose, "Nanocrystalline $\alpha-\mathrm{Al}_{2} \mathrm{O}_{3}$ using sucrose". J. Am. Ceram. Soc., 84 (2001) 2421-2423.

98. P. Wang, C. Wang, L. Lin, Y. Zhu, Y. Xie, "Efficient preparation of submicrometer $\alpha$-alumina powders by calcining Carbon-Covered Alumina". J. Am. Ceram. Soc., 89 (2006) 2744-2748.

99. R. Septawendar, S. Edwin, F. Edwin, "Nanocrystalline $\alpha-\mathrm{Al}_{2} \mathrm{O}$, powder preparation with sucrose as a template through a chemical route,". J. Ceram. Process. Res., 12 (2011) 365-370. 
100. K.A. Evans, "The manufacture of alumina and its use in ceramics and related applications". Key Eng. Mat., 122-124 (1996) 489-526.

101. U. Takase, T. Sata, "Formation mechanism of ultra-fine alumina particle from $\mathrm{NH}_{3}$ gas - $\mathrm{AlCl}_{3}$ solution". J. Ceram. Assoc. Japan, 8 (1979) 495-500.

102. P.V. Ananthapadmanabhan, T.K. Thiyagarajan, K.P. Sreekumar, N. Venkatramani, "Formation of nano-sized alumina by in-flight oxidation of aluminium powder in a thermal plasma reactor". Scripta Mater., 50 (2004) 143-147.

103. R.W. Siegel, H. Hahn, J.A. Eastman, "Method of making nanocrystalline alpha alumina". Patente n": (EE.UU., 7/1992).

104. L.P.H. Jeurgens, W.G. Sloof, F.D. Tichelaar, E.J. Mittemeijer, "Structure and morphology of aluminium-oxide films formed by thermal oxidation of aluminium". Thin Solid Films, 418 (2002) 89-101.

105. P. Wong, M. Robinson, "Chemical vapor deposition of polycrystalline $\mathrm{AlO}^{\prime \prime}$. J. Am. Ceram. Soc., 53 (1970) 617-621.

106. E. Elaloui, A.C. Pierre, G.M. Pajonk, "Influence of the sol-gel processing method on the structure and the porous texture of nondoped aluminas". J. Catal., 166 (1997) 340-346.

107. Y. Sarika, M. Akinc, "Preparation of alumina microshells by the emulsion evaporation technique". Ceram. Int., 14 (1988) 239-244.

108. Y. Sarikaya, T. Alemdaroglu, M. Onal, "Determination of the shape, size, and porosity of fine alpha- $\mathrm{Al}_{2} \mathrm{O}_{3}$ powders prepared by emulsion evaporation". J. Eur. Ceram. Soc., 22 (2002) 305-309.

109. Y.C. Lee, S.B. Wen, L. Wenglin, "Nano $\alpha-\mathrm{Al}_{2} \mathrm{O}_{3}$ powder preparation by calcining an emulsion precursor". J. Am. Ceram. Soc., 90 (2007) 17231727.

110. P.K. Panda, V.A. Jaleel, S.U. Devi, “Hydrothermal synthesis of boehmite and $\alpha$-alumina from Bayer's alumina trihydrate". J. Mater. Sci., 41 (2006) 8386-8389.

111. K.X. Song, S.Y. Wu, X.M. Chen, N. Qin, "Glycothermal synthesis of $\alpha-\mathrm{Al}_{2} \mathrm{O}_{3}$ in 1,4-butadional organic solvent". J. Electroceram., 21 (2008) 805-809.

112. S.G. Deng, Y.S. Lin, "Microwave synthesis of mesoporous and microporous alumina powders". J. Mater. Sci. Lett., 16 (1997) 1291-1294.

113. H.K. Varma, T.V. Mani, A.D. Damodaran, K.G. Warrier, U. Balachandran, "Characteristics of alumina powders prepared by spray-drying of boehmite sol". J. Am. Ceram. Soc., 77 (1994) 1597-1600.

114. C. Tallón, R. Moreno, M.I. Nieto, "Synthesis of $\gamma-\mathrm{Al}_{2} \mathrm{O}_{3}$ nanopowders by freeze-drying". Mater. Res. Bull., 41 (2006) 1520-1529.

115. J.H. Kim, K.Y. Jung, K.Y. Park, S.B. Cho, “Characterization of mesoporous alumina particles prepared by spray pyrolysis of $\mathrm{Al}\left(\mathrm{NO}_{3}\right)_{2} \bullet 9 \mathrm{H}_{2} \mathrm{O}$ precursor: Effect of CTAB and urea". Micropor. Mesopor. Mat., 128 (2010) 85-90.

116. K.N. Rai, E. Ruckenstein, "Alumina substrates with cylindrical parallel pores". J. Catal., 40 (1975) 117-123.

117. N. Itoh, K. Kato, T. Tsuji, M. Hongo, "Preparation of a tubular anodic aluminum oxide membrane". J. Membrane Sci., 117 (1996) 189-196.

118. P.H. Hsu, T.F. Bates, "Formation of X-ray amorphous and crystalline aluminium hydroxides". Mineral. Mag., 83 (1964) 749-768.

119. J.E. Blendell, H.K. Bowen, R.L. Coble, "High purity alumina by controlled precipitation from aluminum sulfate solutions". Am. Ceram. Soc. Bull., 63 (1964) 797-802

120. K.M. Parida, A.C. Pradhan, J. Das, N. Sahu, "Synthesis and characterization of nano-sized porous gamma-alumina by control precipitation method". Mater. Chem. Phys., 113 (2009) 244-248.

121. M.M. Martín-Ruiz, L.A. Pérez-Maqueda, T. Cordero, V. Balek, J. Subrt, N. Murafa, J. Pascual-Cosp, "High surface area $\alpha$-alumina preparation by using urban waste". Ceram. Int., 35 (2009) 2111-2117.

122. W.B. Scott, E. Matijevic, "Aluminum hydrous oxide sols. III. Preparation of uniform particles by hydrolysis of aluminum chloride and perchlorate salts". J. Colloid Interf. Sci., 66 (1978) 447-454.

123. E. Morgado, Y.L. Lam, L.F. Nazar, "Formation of peptizable boehmites by hydrolysis of aluminum nitrate in aqueous solution". J. Colloid Interf. Sci., 188 (1997) 257-269.

124. E.M. Jr., Y.L. Lam, L.F. Nazar, "Formation of peptizable boehmites by hydrolysis of aluminum nitrate in aqueous solution". J. Colloid Interf. Sci., 188 (1997) 257-269.

125. M.I.F. Macedo, C.C. Osawa, C.A. Bertran, "Sol-gel synthesis of transparent alumina gel and pure gamma alumina by urea hydrolysis of aluminum nitrate". J. Sol-Gel Sci. Techn., 30 (2004) 135-140.

126. E. Ponthieu, E. Payen, G.M. Pajonk, J. Grimblot, “Comparison of drying procedures for the preparation of alumina powders with the system Al-alkoside/tertiary butanol/water". J. Sol-Gel Sci. Techn., 8 (1997) 201206.

127. J. Sanchez-Valente, X. Bokhimi, J.A. Toledo, "Synthesis and catalytic properties of nanotructured aluminas obtained by the sol-gel method". Appl. Catal. A-Gen., 264 (2004) 175-181.

128. G.L. Teoh, K.Y. Liew, W.A.K. Mahmood, "Synthesis and characterization of sol-gel alumina nanofibers". J. Sol-Gel Sci. Techn., 44 (2007) 177-186.

129. B.E. Yoldas, "Alumina gels that form porous transparent $\mathrm{Al}_{2} \mathrm{O}_{3}$ ". J. Mater. Sci., 10 (1975) 1856-1860.

130. N.Y. Turova, E.P. Turevskaya, V.G. Kessler, M.I. Yanovskaya. The Chemistry of Metal Alkoxides. (Kluwer Academic Publishers, New York, 2002).
131. R. Bosco, B.V. Kamath, K.V. Rao, G.S. Rao, K.R. Krishnamurthy, “Alumina through sol-gel route: influence of preparation parameters". Stud. Surf. Sci. Catal., 113 (1998) 591-598

132. A.J. Léonard, F.V. Cauwelaert, J.J. Fripiat, "Structure and properties of amorphous silicoaluminas III. Hydrated aluminas and transition aluminas". J. Phys. Chem., 71 (1967) 695-708.

133. T.E. Wood, A.R. Siedle, J.R. Hill, R.P. Skarjune, C.J. Goodbrake, “Hydrolysis of Aluminum - Are all gels created equal?" Mater. Res. Soc. Symp. Proc., 180 (1990) 97-116

134. S.M. Bradley, R.A. Kydd, R.F. Howe, "The structure of Al gels formed trough the base hydrolysis of $\mathrm{Al}^{3+}$ aqueous solutions". J. Colloid Interf. Sci., 159 (1993) 405-412

135. U. Janosovits, G. Ziegler, U. Scharf, A. Wokaun, "Structural characterization of intermediate species during synthesis of $\mathrm{Al}_{2} \mathrm{O}_{3}$-aerogels". J. Non-Cryst. Solids, 10 (1997) 1-13.

136. C. Feng, Q. Wei, S. Wang, B. Shi, H. Tang, "Speciation of hydroxyl-Al polymers formed through simultaneous hydrolysis of aluminum salts and urea". Colloid Surface A, 303 (2007) 241-248.

137. K.S.W. Sing, D.H. Everett, R.A.W. Haul, L. Moscou, R.A. Pierotti, J. Rouquérol, T. Siemieniewska, "Reporting physisorption data for gas/ sold systems with special reference to the determination of surface area and porosity (Recommendations 1984)". Pure Appl. Chem., 57 (1985) 603619.

138. B. Kasprzyk, "Chemistry of alumina, reactions in aqueous solution and its application in water treatment". Adv. Colloid Interfac., 110 (2004) 19-48.

139. R. Weingarten, G.A. Tompsett, W. Curtis-Conner, G.W. Huber, “Design of solid acid catalysts for aqueous-phase dehydration of carbohydrates: The role of Lewis and Brønsted acid sites". J. Cat., 279 (2011) 174-182.

140. B. Beguin, E. Garbowski, M. Primet, "Stabilization of alumina toward thermal sintering by silicon addition". J. Catal., 127 (1991) 595-604.

141. P. Burtin, J.P. Brunelle, M. Pijolat, M. Soustelle, "Influence of surface area and additives on the thermal stability of transition alumina catalyst supports. I. Kinetic data". Appl. Catal., 34 (1987) 225-238.

142. J.S. Church, N.W. Cat, D.L. Trimm, "Stabilization of aluminas by rare earth and alkaline earth ions". Appl. Catal. A-Gen., 101 (1993) 105-116.

143. S. Rossignol, C. Kappenstein, "Effect of doping elements on the thermal stability of transition alumina". Int. J. Inorg. Mater., 3 (2001) 51-58.

144. M. Ozawa, Y. Nishio, "Thermal stabilization of $\alpha$-alumina with modification of lanthanum through homogeneous precipitation". J. Alloy Compd., 374 (2004) 397-400

145. O.V. Andryushkova, O.A. Kirichenko, V.A. Ushakov, "Thermal stability of low-temperature alumina sorbents and catalysts". Stud. Surf. Sci. Catal., 120A (1999) 587-619.

146. K. Maeda, F. Mizukami, S. Niwa, M. Toba, M. Watanabe, K. Masuda, "Thermal behaviour of alumina from aluminium alkoxide reacted with complexing agent". J. Chem. Soc. Farad. T., 88 (1992) 97-104.

147. H.Y. Zhu, J.D. Riches, J.C. Barry, " $\gamma$-Alumina nanofibers prepared from aluminum hydrate with poly(ethylene oxide) surfactan". Chem. Mater., 14 (2002) 2086-2093.

148. G.K. Chuah, S. Jaenicke, T.H. Xu, "The effect of digestion on the surface area and porosity of alumina". Micropor. Mesopor. Mat., 37 (2000) 345-353.

149. Q. Liu, A. Wang, X. Wang, T. Zhang, "Morphologically controlled synthesis of mesoporous alumina". Micropor. Mesopor. Mat., 100 (2007) $35-44$.

150. Z. Gan, G. Ning, Y. Lin, Y. Cong, "Morphological control of mesoporous alumina nanostructures via template-free solvothermal synthesis". Mater. Lett., 61 (2007) 3758-3761.

151. Y. Liu, D.Ma, X. Han, X. Bao, W. Frandsen, D. Wang, D. Su, “Hydrothermal synthesis of microscale boehmite and gamma nanoleaves alumina". Mater. Lett., 62 (2008) 1297-1301.

152. M. Digne, R. Revel, M. Boualleg, D. Chiche, B. Rebours, M. Moreaud, B. Celse, C. Chanéac, J.P. Jolivet, "Innovative characterizations and morphology control of $\gamma-\mathrm{AlOOH}$ boehmite nanoparticles: towards advanced tuning of $\gamma-\mathrm{Al}_{2} \mathrm{O}_{3}$ catalyst properties". Stud. Surf. Sci. Cat., 175 (2010) 127-134

153. M. Crisan, M. Zaharescu, V.D. Kumari, M. Subrahmanyam, D. Crisan, N. Dragan, M. Raileanu, M. Jitianu, A. Rusu, G. Sadanandam, J.K. Reddy, "Sol-gel based alumina powders with catalytic applications". Appl. Surf. Sci., 258 (2011) 448-455

154. D.L. Trimm, A.S. Stanislaus, "The control of pore size in alumina catalyst supports: A review". Appl. Catal., 21 (1986) 215-238.

155. F. Schüth, "Endo- and exotemplating to create high-surface-area inorganic materials". Angew. Chem. Int. Edit., 42 (2003) 3604-3622.

156. C. Márquez-Álvarez, N. Zilkova, J. Perez-Pariente, J. Cejka, “Synthesis, characterization and catalytic applications of organized mesoporous alumina". Catal. Rev., 50 (2008) 222-286.

157. Z. Wu, Q. Li, D. Feng, P.A. Webley, D. Zhao, "Ordered mesoporous crystalline $\gamma-\mathrm{Al}_{2} \mathrm{O}_{3}$ with variable architecture and porosity from a single hard template". J. Am. Chem. Soc., 132 (2010) 12042-12050.

158. Q. Liu, A. Wang, J. Xu, Y. Zhang, X. Wang, T. Zhang, "Preparation of ordered mesoporous crystalline alumina replicated by mesoporous carbon". Micropor. Mesopor. Mat., 116 (2008) 461-468. 
159. P. Colombo, "Conventional and novel processing methods for cellular ceramics". Philos. T. Roy. Soc. A 364 (2006) 109-124.

160. A.R. Studart, U.T. Gonzenbach, E. Tervoort, L.J. Gauckler, "Processing routes to macroporous ceramics: A review". J. Am. Ceram. Soc., 89 (2006) 1771-1789.

161. O. Lyckfeldt, J.M.F. Ferreira, "Processing of porous ceramics by "starch consolidation"”". J. Eur. Ceram. Soc., 18 (1998) 131-140.

162. G.J. Zang, J.F. Yang, T. Ohji, "Fabrication of porous ceramics with unidirectionally aligned continuous pores". J. Am. Ceram. Soc., 84 (2001) 1395-1397.

163. X.J. Ding, J.Z. Zhang, R.D. Wang, C.D. Feng, “Formation of porous alumina with oriented pores". J. Eur. Ceram. Soc., 2 (2002) 411-414.

164. S. Sokolov, D. Bell, A. Stein, "Preparation and characterization of macroporous $\alpha$-alumina". J. Am. Ceram. Soc., 86 (2003) 1481-1486.

165. T. Isobe, T. Tomita, Y. Kameshima, A. Nakajima, K. Okada, "Preparation an properties of porous alumina ceramics with oriented cylindrical pores produced by an extrusion method". J. Eur. Ceram. Soc., 2 (2006) 957-960.

166. X. Mao, S. Shimai, S. Wang, "Gelcasting of alumina foams consolidated by epoxy resin". J. Eur. Ceram. Soc., 28 (2008) 217-222.

167. C. Tallón, R. Moreno, M.I. Nieto, "Shaping of porous alumina bodies by freeze casting". Adv. Appl. Ceram., 108 (2009) 307-313.

168. X. Guo, Z. Zhou, G. Ma, S. Wang, S. Zhao, Q. Zhang, "Effect of forming process on the integrity of pore-gradient $\mathrm{Al}_{2} \mathrm{O}_{3}$ ceramic foams by gelcasting". Ceram. Int., 38 (2012) 713-719.

169. C. Lesaint, G. Kleppa, D. Arla, W.R. Glomm, G. Øye, "Synthesis and characterization of mesoporous alumina materials with large pore size prepared by a double hydrolysis route". Micropor. Mesopor. Mat., 119 (2009) 245-251.

170. L.L. Li, W.T. Duan, Q. Yuan, Z.X. Li, H.H. Duan, C.H. Yan, “Hierarchical $\gamma-\mathrm{Al}_{2} \mathrm{O}_{3}$ monoliths with highly ordered 2D hexagonal mesopores in macroporous walls". Chem. Commun. (2009) 6174-6176.

171. S.W. Bian, Y.L. Zhang, H.L. Li, Y. Yu, Y.L. Song, W.G. Song, " $\gamma$-Alumina with hierarchically ordered mesopore/macropore from dual templates". Micropor. Mesopor. Mat., 131 (2010) 289-293.

172. Q. Wu, F. Zhang, J. Yang, Q. Li, B. Tu, D. Zhao, "Synthesis of ordered mesoporous alumina with large pore sizes and hierarchical structure". Micropor. Mesopor. Mat., 143 (2011) 406-412.

173. A. Stanislaus, K. Al-Dolama, M. Absi-Halabi, "Preparation of a large pore alumina-based HDM catalyst by hydrothermal treatment and studies on pore enlargement mechanism". J. Mol. Catal. A-Chem., 181 (2002) 33-39.

174. W. Deng, B.H. Shanks, "Synthesis of hierarchically structured aluminas under controlled hydrodynamic conditions". Chem. Mater., 17 (2005) 30923100.

175. A.B. Sifontes, M. Urbina, F. Fajardo, L. Melo, L. García, M. Mediavilla, N Carrión, J.L. Brito, "Preparation of $\gamma$-alumina ceramic foams employing hydrophilated polyester polyurethane sponges". J. Mater. Sci., 44 (2009) 4507-4509.

176. J.P. Dacquin, J. Dhainaut, D. Duprez, S. Royer, A.F. Lee, K. Wilson, “An efficient route to highly organized, tunable macroporous-mesoporous alumina". J. Am. Ceram. Soc., 131 (2009) 12896-12897.

177. H.L. Mitchell, "High surface area alpha aluminas". Patente $n^{\circ}: 4012337$ (EE.UU., 3/1977)

178. C.F. Mao, M.A. Vannice, "High surface area $\alpha$-alumina. I. Adsorption properties and heats of adsorption of carbon monoxide, carbon dioxide, and ethylene". Appl. Catal. A-Gen., 111 (1994) 151-173.

179. A.J. Perrota, "Nanosized corundum synthesis". Mater. Res. Innov., 2 (1998) 33-38.

180. P.A. Zielinski, R. Schulz, S. Kaliaguine, A.V. Neste, "Structural transformations of alumina by high energy ball milling". J. Mater. Res., 8 (1993) 2985-2992

181. E. Kostić, S.J. Kiss, S. Zec, S. Boskovic, "Transition of $\gamma-\mathrm{Al}_{2} \mathrm{O}_{3}$ into $\alpha-\mathrm{Al}_{2} \mathrm{O}_{3}$ during vibro milling". Powder Technol., 107 (2000) 48-53.

182. G.R. Karagedov, N.Z. Lyakhov, "Preparation and sintering of nanosized $\alpha-\mathrm{Al}_{2} \mathrm{O}_{3}$ powder". Nanostruct. Mater., 11 (1999) 559-572.

183. A.J.L. Toombs, W.E. Armstrong, "Production of catalyst or catalysts support". Patente $n^{\circ}: 3726811$ (EE.UU., 4/1973)

184. H.V. Holler, "Production of alpha alumina". Patente $n^{\circ}: 3908002$ (EE.UU. 9/1975).

185. L.L. Murrell, D.C. Grenoble, J.P. DeLuca, “Process for preparing ulta-sable, high surface area alpha-alumina". Patente $n^{\circ}:$ 416988. (EE.UU., 10/1979).

186. H. Liu, G. Ning, Z. Gan, Y. Lin, “Emulsion-based synthesis of unaggregated, spherical alpha alumina". Mater. Lett. , 62 (2008) 1685-1688.

187. Y. Sarikaya, I. Sevinc, M. Akinc, "The effect of calcination temperature on some of the adsorptive properties of fine alumina powders obtained by emulsion evaporation technique". Powder Technol., 116 (2001) 109-114.

188. W.M. Zen, L. Gao, J.K. Guo, "A new sol-gel route using inorganic salt for synthesizing $\mathrm{Al}_{2} \mathrm{O}$ nanopowders". Nanostructur. Materd., 10 (1998) 543550.
189. J. Pascual-Cosp, A.J.R.d. Valle, J.C.G. Serrano, T.C. Alcántara, V. Balik, Z. Cerny, B. Casensky, "Manufactuing of $\alpha-\mathrm{Al}_{2} \mathrm{O}_{3}$ with high specific surface using urban waste and materials from uranium extractive metallurgy". Key Eng. Mat., 264-268 (2004) 2441-2444.

190. A.H. Heuer, D.J. Fink, V.J. Arias, P.D. Calvert, K. Kendali, G.L. Messing, J. Blackwell, P.C. Rieke, D.H. Thopson, A.P. Wheeler, A. Veis, A.I. Caplan, "Innovative materials processing strategies: A biomimetic approach". Science, 255 (1992) 1098-1105.

191. P. Ball, "Life's lessons in design". Nature, 409 (2001) 413-416.

192. P. Greil, "Biomporphous ceramics from lignocellulosics". J. Eur. Ceram Soc., 21 (2001) 105-118.

193. T.X. Fan, S.K. Chow, D. Zhang, "Biomorphic mineralization: From biology to materials". Prog. Mater. Sci. , 54 (2009) 542-659.

194. N. Travitzky, H. Windsheimer, T. Fey, P. Greil, "Preceramic paper-derived ceramics". J. Am. Ceram. Soc., 91 (2008) 3477-3492.

195. C.E. Byrne, D.C. Nagle, "Cellulose derived composites - A new method for materials processing". Mater. Res. Innov., 1 (1997) 137-144.

196. M. Singh, J. Martínez-Fernández, A.R.d. Arellano-López, "Environmentally conscious ceramics (ecoceramics) from natural wood precursors". Curr. Opin. Solid St. M., 7 (2003) 247-254.

197. H. Sieber, "Biomimetic synthesis of ceramics and ceramic composites". Mat. Sci. Eng. A-Struct., 412 (2005) 43-47.

198. M. Singh, B.M. Yee, "Reactive processing of environmentally conscious, biomorphic ceramics from natural wood precursors". J. Eur. Ceram. Soc., 24 (2004) 209-217.

199. H. Sieber, M. Singh, Microcellular ceramics from wood. En: M. Scheffler and P. Colombo, eds. Cellular Ceramics: Structure, Manufacturing, Properties and Applications, (Wiley-VCH, Weinheim, 2005), pp. 122-136.

200. H. Sieber, C. Hoffmann, A. Kaindl, P. Greil, "Biomorphic cellular ceramics". Adv. Eng. Mater., 2 (2000) 105-109.

201. E. Vogli, J. Mukerji, C. Hoffmann, R. Kladny, H. Sieber, P. Greil, "Conversion of oak to cellular silicon carbide ceramics by gas-phase reaction with silicon monoxide". J. Am. Ceram. Soc., 84 (2001) 1236-1240.

202. E. Vogli, H. Sieber, P. Greil, "Biomorphic SiC-ceramic prepared by Si-vapor phase infiltration of wood". J. Eur. Ceram. Soc., 22 (2002) 2663-2668.

203. J. Cao, C.R. Rambo, H. Sieber, "Manufacturing of microcellular, biomorphous oxide ceramics from native pine wood". Ceram. Int., 30 (2004) 1967-1970.

204. H. Sieber, C. Rambo, J. Cao, E. Vogli, P.Greil, "Manufacturing of porous oxide ceramics by replication of plant morphologies". Key Eng. Mat., 206213 (2002) 2009-2012.

205. M. Patel, B.K. Padhi, "Production of alumina fibre through jute fibre substrate". J. Mater. Sci., 25 (1990) 1335-1343.

206. T. Fan, B. Sun, J. Gu, D. Zhang, L.W.M. Lau, "Biomorphic $\mathrm{Al}_{2} \mathrm{O}_{3}$ fibers synthesized using cotton as biotemplates". Scripta Mater., 53 (2005) 893897

207. T. Fan, X. Li, J. Ding, D. Ding, Q. Guo, "Sythesis of bimorphic $\mathrm{Al}_{2} \mathrm{O}_{3}$ based on natural plant templates and assembly of Ag nanoparticles controlled within the nanopores". Micropor. Mesopor. Mat., 108 (2008) 204-212.

208. J. Cao, C.R. Rambo, H. Sieber, "Preparation of porous $\mathrm{Al}_{2} \mathrm{O}_{3}$-ceramics by biotemplating of wood". J. Porous Mat., 11 (2004) 163-172.

209. C.R. Rambo, H. Sieber, "Novel synthetic route to biomorphic $\mathrm{Al}_{2} \mathrm{O}_{3}$ ceramics". Adv. Mater, 17 (2005) 1088-1091.

210. C.R. Rambo, T. Andrade, T. Fey, H. Sieber, A.E. Martinelli, P. Greil, "Microcellular $\mathrm{Al}_{2} \mathrm{O}_{3}$ ceramics from wood for filter applications". J. Am. Ceram. Soc., 91 (2008).

211. T.E. Andrade, C.R. Rambo, H. Sieber, A.E. Martinelli, D.M.A. Melo, "Hollow biomorphic $\mathrm{Al}_{2} \mathrm{O}_{3}$ fibers produced from sisal". J. Mater. Sci., 42 (2007) 5426-5430.

212. T.E. Andrade, A.E. Martinelli, D.M.A. Melo, R.M. Nascimento, C. Rambo, H. Sieber, P. Greil, "Infiltração de sal de alumínio em fibras de sisal para obtenção de fibras de alumina". Cerâmica, 51 (2005) 37-41.

213. A.N. Shigapov, G.W. Graham, R.W. McCabe, H.K. Plummer, "The preparation of high-surface area, thermally-stable metal-oxide catalysts and supports by cellulose templating approach". Appl. Catal. A-Gen, 210 (2001) 287-300.

214. L. Zhong, Y. Zhang, F. Chen, Y. Zhang, "Synthesis of mesoporous alumina using a recyclable methylcellulose template". Micropor. Mesopor. Mat., 142 (2011) 740-744

215. H. Zhou, T. Fan, D. Zhang, "Biotemplated materials for sustainable energy and environment: Current status and challenges". Chem. Sus. Chem., 4 (2011) 1344-1387

Recibido: 18/04/2013

Recibida versión corregida: 25/10/2013

Aceptado: 29/10/2013 